\title{
Effect of sequestering agents based on a Saccharomyces cerevisiae fermentation product and clay on the ruminal bacterial community of lactating dairy cows challenged with dietary aflatoxin $B_{1}$
}

\author{
Y. Jiang, ๑ I. M. Ogunade,* () A. A. Pech-Cervantes, ๑ P. X. Fan, X. Li,† D. H. Kim,‡ K. G. Arriola, ๑ \\ M. B. Poindexter, K. C. Jeong, D. Vyas, (1) and A. T. Adesogan§ (1) \\ Department of Animal Sciences, University of Florida, Gainesville 32611
}

\begin{abstract}
This study was conducted to examine the effects of clay (CL) and Saccharomyces cerevisiae fermentation product (SCFP) on the ruminal bacterial community of Holstein dairy cows challenged with aflatoxin $\mathrm{B}_{1}$ $\left(\mathrm{AFB}_{1}\right)$. A second objective was to examine correlations between bacterial abundance and performance measures. Eight lactating dairy cows stratified by milk yield and parity were randomly assigned to 4 treatments in a $4 \times 4$ Latin square design with 2 replicate squares, four 33-d periods, and a 5 -d washout between periods. The treatments included (1) control (basal diet, no additive); (2) $\mathrm{T}$ (control $+63.4 \mu \mathrm{g} / \mathrm{kg} \mathrm{AFB}{ }_{1}$, oral dose); (3) CL ( $\mathrm{T}+200 \mathrm{~g} /$ head per day of sodium bentonite clay, top-dress); and (4) CL+SCFP [CL + 19 $\mathrm{g} /$ head per day Diamond V NutriTek (Diamond V Inc., Cedar Rapids, IA) + 16 g/head per day MetaShield (Diamond V Inc.), top-dress]. Cows were adapted to diets containing no $\mathrm{AFB}_{1}$ from d 1 to 25 (predosing period). From d 26 to 30 (dosing period), $\mathrm{AFB}_{1}$ was orally dosed and then withdrawn for d 31 to 33 (withdrawal period). During the predosing period, compared with the control, feeding CL and CL+SCFP increased the relative abundance of the most dominant phylum, Bacteroidetes (55.1 and 55.8 vs. $50.6 \%$, respectively), and feeding CL+SCFP increased Prevotella abundance ( 43.3 and 43.6 vs. $40.0 \%$, respectively). During the dosing period, feeding $\mathrm{AFB}_{1}$ did not affect the ruminal bacterial community, but the relative abundance of Fibrobacteraceae increased with CL+SCFP compared
\end{abstract}

\footnotetext{
Received April 24, 2019.

Accepted September 26, 2019.

*Current address: Division of Food and Animal Science, Kentucky State University, Frankfort, KY 40601.

$\dagger$ Current address: School of Agriculture and Biology, Shanghai Jiao Tong University, Shanghai, 200240, China.

$\ddagger$ Current address: National Institute of Animal Science, RDA, Cheonan, 31000, Korea.

§Corresponding author: adesogan@ufl.edu
}

with T (1.45 vs. $0.97 \%)$; Fibrobacter abundance also tended to increase with CL+SCFP compared with $\mathrm{T}$ and control, respectively (1.45 vs. 0.97 and $1.05 \%$, respectively). Feeding $\mathrm{AFB}_{1}$ with or without $\mathrm{CL}$ or $\mathrm{CL}+\mathrm{SCFP}$ did not affect ruminal $\mathrm{pH}$ or concentrations of $\mathrm{NH}_{3}-\mathrm{N}$, total volatile fatty acids, or individual volatile fatty acids. Milk yield and milk component yields were positively correlated with the relative abundance of unclassified Succinivibrionaceae, unclassified YS2, or Coprococcus. Feed efficiency was positively correlated $(\mathrm{r} \geq 0.30)$ with the relative abundance of unclassified YS2, Coprococcus, or Treponema. Feeding aflatoxin at $63 \mu \mathrm{g} / \mathrm{kg}$, a common contamination level on farms, did not affect the abundance of dominant bacteria or rumen fermentation. When aflatoxin was fed, CL+SCFP increased the abundance of Fibrobacter, a major fibrolytic bacteria genus. Milk yield and DMI were positively correlated with abundance of Succinivibrionaceae and Coprococcus. Feed efficiency was positively correlated with abundance of Coprococcus, Treponema, and YS2. Future studies should speciate culture and determine the functions of the bacteria to elucidate their roles in the rumen and potential contribution to increasing the performance of dairy cows.

Key words: aflatoxin, clay, yeast fermentation product, rumen bacteria

\section{INTRODUCTION}

Aflatoxins, secondary metabolites of fungi Aspergillus flavus and Aspergillus parasiticus, are recognized as genotoxic and are among the most potent hepatocarcinogenic substances (Zain, 2011). They reduce milk production and quality and compromise immune and ruminal function in dairy cows (Ogunade et al., 2018). Aflatoxin contamination of corn alone causes economic losses estimated at \$163 million annually in the United States (Wu, 2006). Further, approximately 4 to $20 \%$ (\$8.8 to $\$ 44$ million) of the total corn exports from the United States, worth a total of $\$ 220$ million on average, 
can be lost due to aflatoxin contamination based on the US Food and Drug Administration (FDA; $20 \mu \mathrm{g} / \mathrm{kg}$ ) and European Union $(4 \mu \mathrm{g} / \mathrm{kg})$ standards, respectively $(\mathrm{Wu}, 2006)$. Because several other livestock feeds can be contaminated by the toxin, the economic impact is likely to be considerably greater than indicated above.

Ruminants are more resistant to other mycotoxins, such as diacetoxyscirpenol, deoxynivalenol, zearalenone, ochratoxin A, verrucarin, and T-2 toxin, because ruminal microorganisms can biodegrade them (Kiessling et al., 1984; Westlake et al., 1987; Upadhaya et al., 2010). However, only 10 to $50 \%$ of aflatoxin $\mathrm{B}_{1}$ can be degraded by ruminal microbes, as shown in several in vitro studies with incubation durations of 3 to $12 \mathrm{~h}$ (Kiessling et al., 1984; Westlake et al., 1989; Upadhaya et al., 2010).

Mycotoxins can alter the microbial population and composition in the rumen. Strobel et al. (2008) reported that the mycotoxin-producing fungus Fusarium culmorum increased abundance of total fungi, with altered phylogenetic clusters of some major bacteria, such as Fibrobacteriales and Clostridiales, in a rumen-simulating system. In addition, aflatoxin contamination has been shown to negatively affect rumen fermentation in several in vitro studies. Westlake et al. (1989) reported that 1,000 and $10,000 \mu \mathrm{g} / \mathrm{L}$ of aflatoxin $\mathbf{B}_{1}\left(\mathbf{A F B}_{1}\right)$ inhibited in vitro ruminal degradation of alfalfa hay by 50 and $67 \%$, respectively. Similarly, 320, 640, and $960 \mu \mathrm{g} / \mathrm{L} \mathrm{AFB}_{1}$ decreased in vitro ruminal $\mathrm{NH}_{3}-\mathrm{N}$ and total VFA concentrations (Jiang et al., 2012). While several in vitro studies have reported negative effects of aflatoxin on ruminal fermentation, the results are not representative of in vivo conditions because these models do not account for absorption of aflatoxin into the bloodstream after ingestion (Gallo et al., 2008). Furthermore, the levels of aflatoxin contamination used for in vitro studies (320 to $1,000 \mu \mathrm{g} / \mathrm{L}$ in the inoculum) are not representative of the rumen condition. A study by Sulzberger et al. (2017) showed that $\mathrm{AFB}_{1}$ concentration in the rumen was only $0.10 \mu \mathrm{g} / \mathrm{L}$ in cows challenged with $100 \mu \mathrm{g} \mathrm{AFB}_{1} / \mathrm{kg}$ of DMI. Moreover, the average aflatoxin contamination level in more than 7,000 livestock feed samples was reported to be $63 \mu \mathrm{g} /$ $\mathrm{kg}$ of DM (Rodrigues and Naehrer, 2012).

Sequestering agents can reduce transfer of $\mathrm{AFB}_{1}$ to the milk through chemisorption of aflatoxin in the gastrointestinal tract, which reduces its absorption by animals (Diaz et al., 2004). Reduction in milk aflatoxin $\mathrm{M}_{1}$ $\left(\mathbf{A F M}_{1}\right)$ concentrations has been achieved in several studies by feeding certain clays or hydrated sodium calcium aluminosilicates to dairy cows (Kutz et al., 2009; Queiroz et al., 2012; Xiong et al., 2015). Sequestering agents containing modified yeast culture and clay reduced transfer of $\mathrm{AFB}_{1}$ to the milk by $58.5 \%$ (Diaz et al., 2004), although the dietary aflatoxin challenge in that study was relatively low $(55 \mu \mathrm{g} / \mathrm{kg})$. Feeding $S a c$ charomyces cerevisiae fermentation product (SCFP) has been shown to alter the ruminal microbial community in dairy cows (Zhu et al., 2017), which may lead to ruminal $\mathrm{AFB}_{1}$ degradation; however, this possibility has yet to be proved. Our companion study (Jiang et al., 2018) showed that adding clay or clay and SCFP to aflatoxin-contaminated $(63.4 \mu \mathrm{g} / \mathrm{kg}$ of $\mathrm{DM})$ feed reduced milk $\mathrm{AFM}_{1}$ concentrations of lactating dairy cows below the FDA action level $(0.5 \mu \mathrm{g} / \mathrm{kg})$, but only the latter treatment increased milk production.

Ruminal microbes are important for maintaining animal health and performance, however, to our knowledge, no studies have investigated the effects of dietary $\mathrm{AFB}_{1}$ with or without supplementation of clay and SCFP on the ruminal bacterial community of dairy cows. In the current study, our first objective was to examine the effects of supplementing bentonite clay (CL) with or without SCFP on the ruminal fermentation and bacterial community of dairy cows challenged with $\mathrm{AFB}_{1}$. Our second objective was to examine the correlation between the relative abundance of individual ruminal bacteria and performance measurements. Our first hypothesis was that aflatoxin would reduce bacterial diversity in the rumen, which could be prevented by feeding the CL alone or CL and SCFP. Our second hypothesis was that strong positive correlations would exist between dairy cow performance measures and ruminal abundance of certain bacteria.

\section{MATERIALS AND METHODS}

\section{Animals and Treatments}

Cows used in this study were cared for according to the University of Florida Animal Research Committee protocols, developed according to the Guide for the Care and Use of Agricultural Animals in Research and Teaching (FASS, 2010). Eight multiparous $(70 \pm 11$ DIM, parity 2-4) Holstein cows were stratified by parity and milk production and assigned to 1 of 4 treatment sequences arranged in a balanced $4 \times 4$ Latin square design with 2 replicate squares, four 33-d experimental periods, and a 5 -d washout between periods. Cows were housed in a freestall barn with sand-bedded stalls and individual feeding gates (Calan gates, American Calan Inc., Northwood, NH). The experimental pens were equipped with 2 rows of misters and fans facing both the feed lane and bedded stalls and activated when the ambient temperature exceeded $21.1^{\circ} \mathrm{C}$ to minimize heat stress. The treatments were (1) control diet (control; basal diet with no additive); (2) aflatoxin $\operatorname{diet~(T;~oral~}$ dose of $1,725 \mu \mathrm{g}$ of $\mathrm{AFB}_{1} /$ head per day, equivalent to 
$63.4 \mu \mathrm{g} / \mathrm{kg}$ diet DM); (3) aflatoxin-contaminated diet fed with clay $(\mathbf{C L} ; 200 \mathrm{~g} / \mathrm{head} / \mathrm{d}$; Astra-Ben-20, Prince Agri Products Inc., Quincy, IL); and (4) aflatoxincontaminated diet fed with CL and SCFP [CL+SCFP, 200 and $35 \mathrm{~g} /$ head per day, respectively; SCFP, $19 \mathrm{~g}$ of NutriTek (Diamond V Inc., Cedar Rapids, IA) + $16 \mathrm{~g}$ of MetaShield, Diamond V Inc.]. Before the experiment started, cows were adapted to the Calan gates system for $10 \mathrm{~d}$. Clay or CL+SCFP was top-dressed on the respective TMR during the morning feeding from d 1 to 33 of each period, with the first $25 \mathrm{~d}$ of each period considered the adaptation period. Diet composition is shown in Supplemental Table S1 (https://doi .org/10.3168/jds.2019-16851). Morning feedings were closely monitored to ensure complete consumption of the top-dressed clay or SCFP. During the predosing period, animals on $\mathrm{T}$ treatment were fed the same basal diet as the control group. During the dosing period, cows in treatments $\mathrm{T}, \mathrm{CL}$, and $\mathrm{CL}+\mathrm{SCFP}$ were orally dosed with $1,725 \mu \mathrm{g} \mathrm{AFB}_{1}$ from d 26 to 30 (dosing period) before the morning feeding to give a dietary $\mathrm{AFB}_{1}$ concentration of $63.4 \mu \mathrm{g} / \mathrm{kg}$ based on an estimated DMI of $27 \mathrm{~kg} / \mathrm{d}$. Aflatoxin $\mathrm{B}_{1}$ was obtained from an Aspergillus parasiticus (NRRL-2999) culture at the University of Missouri Diagnostic Laboratory (Columbia, MO). It contained $64.1 \% \mathrm{AFB}_{1}, 2.2 \%$ aflatoxin $\mathrm{B}_{2}, 33.4 \%$ aflatoxin $\mathrm{G}_{1}$, and $0.3 \%$ aflatoxin $\mathrm{G}_{2}$. The $\mathrm{AFB}_{1}$ was mixed with $10 \mathrm{~g}$ of ground corn and $4 \mathrm{~mL}$ of molasses and weighed into gelatin capsules, which were orally administered with a balling gun. Control animals were similarly dosed with gelatin capsules that did not contain $\mathrm{AFB}_{1}$. The dietary ingredients and chemical composition of the experimental diet were described in our companion study (Jiang et al., 2018).

\section{Sampling and Measurements}

Ruminal Fluid Collection. Approximately 200 $\mathrm{mL}$ of ruminal fluid was collected $4 \mathrm{~h}$ after the morning feeding on d 25 and 30 of each period using an orally administered stomach tube connected to a vacuum pump (Ruminator; profs-products.com, Wittibreut, Bayern, Germany). About $200 \mathrm{~mL}$ of rumen fluid was taken after discarding the first $200 \mathrm{~mL}$ rumen fluid to reduce saliva contamination. Rumen fluid was filtered through 4 layers of cheesecloth, and $\mathrm{pH}$ was measured with a pH meter (Accumet AB15, Fisher Scientific, Hampton, $\mathrm{NH})$. Approximately $40 \mathrm{~mL}$ of ruminal fluid from each sample was stored at $-80^{\circ} \mathrm{C}$ for analysis of bacterial diversity and abundance. Exactly $400 \mu \mathrm{L}$ of $50 \% \mathrm{H}_{2} \mathrm{SO}_{4}$ was added to each of another set of $40-\mathrm{mL}$ samples, and these were subsequently centrifuged at $11,500 \times g$ for $20 \mathrm{~min}$. The supernatant was stored at $-20^{\circ} \mathrm{C}$ for analysis of VFA and $\mathrm{NH}_{3}-\mathrm{N}$. Saliva contamination of ruminal fluid was not evident in our samples based on Lodge-Ivey et al. (2009).

Measurement of VFA and $\mathrm{NH}_{3}-\mathrm{N}$. Concentrations of lactate, acetate, propionate, butyrate, isobutyrate, isovalerate, and 2-methylbutyrate (which co-elutes with isovalerate under the assay conditions) were measured using an HPLC (FL 7485, Hitachi, Tokyo, Japan) according to the method of Muck and Dickerson (1988). The column (Aminex HPX-87H, Bio-Rad Laboratories, Hercules, CA) used a $0.015 \mathrm{M} \mathrm{H}_{2} \mathrm{SO}_{4}$ mobile phase and a flow rate set at $0.7 \mathrm{~mL} / \mathrm{min}$ at $45^{\circ} \mathrm{C}$ and was connected to a UV detector (Spectroflow 757, ABI Analytical Kratos Division, Ramsey, NJ) set at $210 \mathrm{~nm}$. Concentrations of $\mathrm{NH}_{3}-\mathrm{N}$ were measured using an autoanalyzer (Technicon, Tarrytown, NY) that quantifies nitrogen colorimetrically based on the method adapted by Noel and Hambleton (1976).

DNA Extraction and Preparation. Ruminal fluid samples were thawed at room temperature (about $22^{\circ} \mathrm{C}$ ) and DNA was extracted and purified using the PowerLyzer PowerSoil DNA isolation kit (MOBIO Laboratories Inc., Carlsbad, CA) with bead beating, following the manufacturer's protocol. Bead beating (Bullet159 Blender Storm 24, Next Advance, Averill Park, NY) was used to homogenize the suspension and mechanically disrupt the bacterial cells. It entailed 3 min of beating using $0.1-\mathrm{mm}$ beads, followed by $15 \mathrm{~min}$ at $70^{\circ} \mathrm{C}$ without beating and then another $3 \mathrm{~min}$ of bead beating using the same beads. The DNA concentration and purity were measured using a Nanodrop ND-1000 (Thermo Fisher Scientific, Waltham, MA). The mean DNA concentration of samples was $119 \mathrm{ng} / \mu \mathrm{L}$, and the absorbance (A) ratio at 260 and $280 \mathrm{~nm}\left(\mathrm{~A}_{260} /\right.$ $\mathrm{A}_{280}$ ) ratio was between 1.8 and 2.0. The DNA integrity was verified using agarose $(0.7 \%)$ gel electrophoresis, and extracted DNA was stored at $-80^{\circ} \mathrm{C}$ until further analysis.

Illumina MiSeq $16 S$ rRNA Gene Sequencing. The V4 region of the 16S rRNA gene was PCR amplified with primers 515F/806R (Caporaso et al., 2010). Amplification was performed with AccuPrime Pfx DNA polymerase (Invitrogen, Carlsbad, CA) with an annealing temperature of $55^{\circ} \mathrm{C}$ and 30 cycles (Kozich et al., 2013). The amplicons were purified using a magnetic bead capture kit, Agencourt AMPure XP (Beckman Coulter, Pasadena, CA), and then pooled in equal proportions based on DNA concentration with SequalPrep Normalization Plate Kit (Invitrogen). The concentration of the library was determined with a Kapa qPCR (Kapa Biosystems, Wilmington, MA). The pooled library and a PhiX control v3 (Illumina, San Diego, CA) were mixed with $0.2 \mathrm{~N}$ fresh $\mathrm{NaOH}$ and 
HT1 buffer (Illumina) to yield a final concentration of 6 $\mathrm{p} M$ each. The resulting library was then combined with PhiX control v3 to yield 5\% PhiX control and 95\% 16S rRNA gene amplicon library. The final library $(600 \mu \mathrm{L})$ was loaded into MiSeq v2 with $2 \times 250$ cycle cartridge (Illumina) and sequenced with the Illumina MiSeq platform. The sequencing procedure was monitored on the Illumina BaseSpace website (https://basespace .illumina.com).

Sequence Analysis. Demultiplexed paired-end forward R1 and reverse R2 sequencing read files were obtained from the Illumina BaseSpace website. Sequences were analyzed with the Quantitative Insights into Microbial Ecology (QIIME, v. 1.9.0) according to Caporaso et al. (2010). Chimeras were identified with ChimeraSlayer and removed from subsequent analysis by the script identify_chimeric_seqs.py with the usearch61 option (Edgar, 2010). Paired-end reads were assembled with the multiple_join_paired_ends. py and multiple_split_libraries_fastq.py scripts. From the assembled sequences, operational taxonomic units (OTU) were picked with $97 \%$ identity using the script pick_de_novo_otus.py and classified into the taxonomic levels by Uclust (Edgar, 2010) against the Greengenes reference database (DeSantis et al., 2006). The OTU table was generated with the script make_otu_table.py, and the singletons were removed by filter_otus_from otu_table.py. Sequence data were normalized to 30,640 reads per sample, which is the minimum sequencing depth among the samples before comparing diversity. Within-sample $(\alpha)$ phylogenetic diversity (Shannon) and species richness (Chao 1) were conducted on the normalized OTU table with the script alpha_diversity. py. Between-sample $(\beta)$ diversity was estimated with the script beta_diversity_through_plots.py. Unweighted phylogenetic (UniFrac) distances (Lozupone and Knight, 2005) between sets of taxa in the phylogenetic tree were used to conduct principal coordinate analysis. Analysis of similarities was used to analyze statistical significance of sample groupings using the distance metrics with the script compare_categories.py. Abundance of bacteria at different taxonomical levels was identified with the script summarize_taxa_through_plots. py. Good's coverage was estimated with the formula of 1 - (number of individuals in species/total number of individuals) $\times 100$.

\section{Statistical Analysis}

The within-treatment and between-treatment UniFrac distance was compared by nonparametric Monte Carlo test with no Bonferroni correction with QIIME. The within-sample phylogenetic distance was compared using GLIMMIX procedure of SAS 9.3 (SAS Institute Inc., Cary, NC) at the highest rarefaction depth. The ruminal $\mathrm{pH}$, concentrations of $\mathrm{NH}_{3}-\mathrm{N}$ and VFA, and relative abundance of OTU from different treatments were compared using the GLIMMIX procedure of SAS. The model used was

$$
\mathrm{Y}=\mu+\mathrm{T}_{\mathrm{i}}+\mathrm{P}_{\mathrm{j}}+\mathrm{S}_{\mathrm{k}}+\mathrm{C}_{\mathrm{l}}+(\mathrm{T} \times \mathrm{P})_{\mathrm{ij}}+\varepsilon_{\mathrm{ijklm}},
$$

where $\mathrm{Y}$ is the dependent variable; $\mu$ is the overall mean; $\mathrm{T}_{\mathrm{i}}$ and $\mathrm{P}_{\mathrm{j}}$ are fixed effects of treatment and period, respectively; $(\mathrm{T} \times \mathrm{P})_{\mathrm{ij}}$ is the interaction between treatment and period; $S_{k}$ and $C_{l}$ are the random effects of square and cow, respectively; and $\varepsilon_{\mathrm{ijklm}}$ is the residual error.

Model fitness was assessed by examining the distribution of residuals using the Shapiro-Wilk W test with the GLIMMIX procedure. Denominator degrees of freedom were estimated using the Kenward-Roger option in the MODEL statement. Tukey-Kramer pairwise multiple comparisons were used for post hoc mean comparisons. Pearson correlations between dairy cow performance measurements and relative abundance of the individual dominant bacteria families or genera were performed using $\mathrm{R}$ version 3.4.1 (http://www.r-project .org). The measurements of dairy cow performance for each experimental period were averaged for each cow during the predosing and dosing periods for conducting correlation analysis. Significance was declared at $P \leq$ 0.05 and tendencies at $0.05<P \leq 0.10$.

\section{RESULTS}

The effects of supplementing $\mathrm{AFB}_{1}$ with or without $\mathrm{CL}$ and $\mathrm{CL}+\mathrm{SCFP}$ on health and performance of the dairy cows, and milk aflatoxin concentration were reported in a previous study (Supplemental Table S2 and Supplemental Figure S1; https://doi.org/10.3168/jds .2019-16851). Briefly, adding $63.4 \mu \mathrm{g} / \mathrm{kg} \mathrm{AFB}_{1}$ to the diet did not affect milk yield but increased milk $\mathrm{AFM}_{1}$ concentration to $0.75 \mu \mathrm{g} / \mathrm{kg}$, which exceeded the FDA action level $(0.5 \mu \mathrm{g} / \mathrm{kg})$. Meanwhile, $\mathrm{AFM}_{1}$ in milk of cows fed CL or CL+SCFP was 0.45 and $0.40 \mu \mathrm{g} / \mathrm{kg}$, respectively. Compared with feeding $\mathrm{T}$ alone, CL+SCFP tended to increase milk production by $2 \mathrm{~kg} / \mathrm{d}$ and increased milk protein yield by $0.06 \mathrm{~kg} / \mathrm{d}$.

\section{Ruminal Fermentation}

Feeding $\mathrm{AFB}_{1}$ at $63.4 \mu \mathrm{g} / \mathrm{kg}$ with or without the sequestering agents did not affect $(P>0.10$, Table 1$)$ ruminal $\mathrm{pH}, \mathrm{NH}_{3}-\mathrm{N}$, total VFA concentration, or molar 
proportions of individual VFA during the predosing or dosing period.

\section{Sequencing Depth and Coverage}

A total of $8,385,554$ sequences were yielded by sequencing the $\mathrm{V} 4$ region of $16 \mathrm{~S}$ rRNA sequences followed by demultiplexing and assembling the quality-filtered reads. The median sequence length was 251 bases and average coverage was $124,750 \pm 36,569$ sequences per sample. The range of sequence reads per sample was from 30,640 to 100,290 . A total of 23,742 different OTU were detected based on $97 \%$ nucleotide sequence identity between reads.

\section{Within-Sample ( $\alpha$ ) and Between-Sample ( $\beta$ ) Diversity}

The average Good's coverage for all the samples was $0.98 \pm 0.0003$, indicating that on average $98 \%$ of species-level OTU were covered by the sequencing. Within-sample $(\alpha)$ diversity, estimated by Chao 1 (a measure of species richness) and Shannon index (a measure of species diversity and richness), was not different across treatments during the predosing or dosing period (Figures $1 \mathrm{~A}$ and $1 \mathrm{~B}$, Figure $2 \mathrm{~A}$ and $2 \mathrm{~B}, P>$ $0.10)$, respectively. The principal coordinate analysis plot, a measure of between-sample ( $\beta$ ) diversity, showed that treatments did not cluster separately, indicating that the bacterial community composition did not differ across treatments during the predosing (Figure 2A; $P=0.90$ ) or dosing period (Figure 2B; $P=0.99$ ).

\section{Relative Abundance of Taxa}

Among the 11 most dominant phyla (each accounted for at least $0.5 \%$ of the bacterial community; Figure $3 \mathrm{~A})$, Bacteroidetes accounted for $52 \pm 4.7 \%$, followed by Firmicutes and Proteobacteria, accounting for 28 \pm 4.3 and $7 \pm 5.0 \%$ of the total bacterial sequences, respectively.

The 19 most dominant bacterial families, each accounting for more than $1 \%$ of the total bacterial community, are listed in Figure 3B. Prevotellaceae was the most dominant family, accounting for $41 \pm 5.7 \%$ of the total bacterial community, followed by Veillonellaceae and Ruminococcaceae, accounting for $7.2 \pm 1.6$ and 6.9 $\pm 2.0 \%$, respectively. Lachnospiraceae, Succinivibrionaceae, and unclassified Clostridiales represented $6.4 \pm$ $1.3,6.1 \pm 5.3$, and $6.0 \pm 1.4 \%$, respectively. Unclassified Paraprevotellaceae, unclassified Bacteroidales, Methanobacteriaceae, and Spirochaetaceae accounted for $5 \pm 1.4,4 \pm 1.6,3 \pm 1.3$, and $2 \pm 0.7 \%$ of total bacterial sequences, respectively.

Among dominant bacterial genera (Figure 3C), Prevotella was the most prevalent genus, accounting for $40.6 \pm 5.2 \%$ of all bacterial genera. The other dominant

Table 1. Effects of dosing aflatoxin $\mathrm{B}_{1}\left(\mathrm{AFB}_{1}\right)$ with or without clay $(\mathrm{CL})$ and Saccharomyces cerevisiae fermentation product $(\mathrm{SCFP})^{1}$ on ruminal fermentation $4 \mathrm{~h}$ after feeding during the predosing and dosing periods

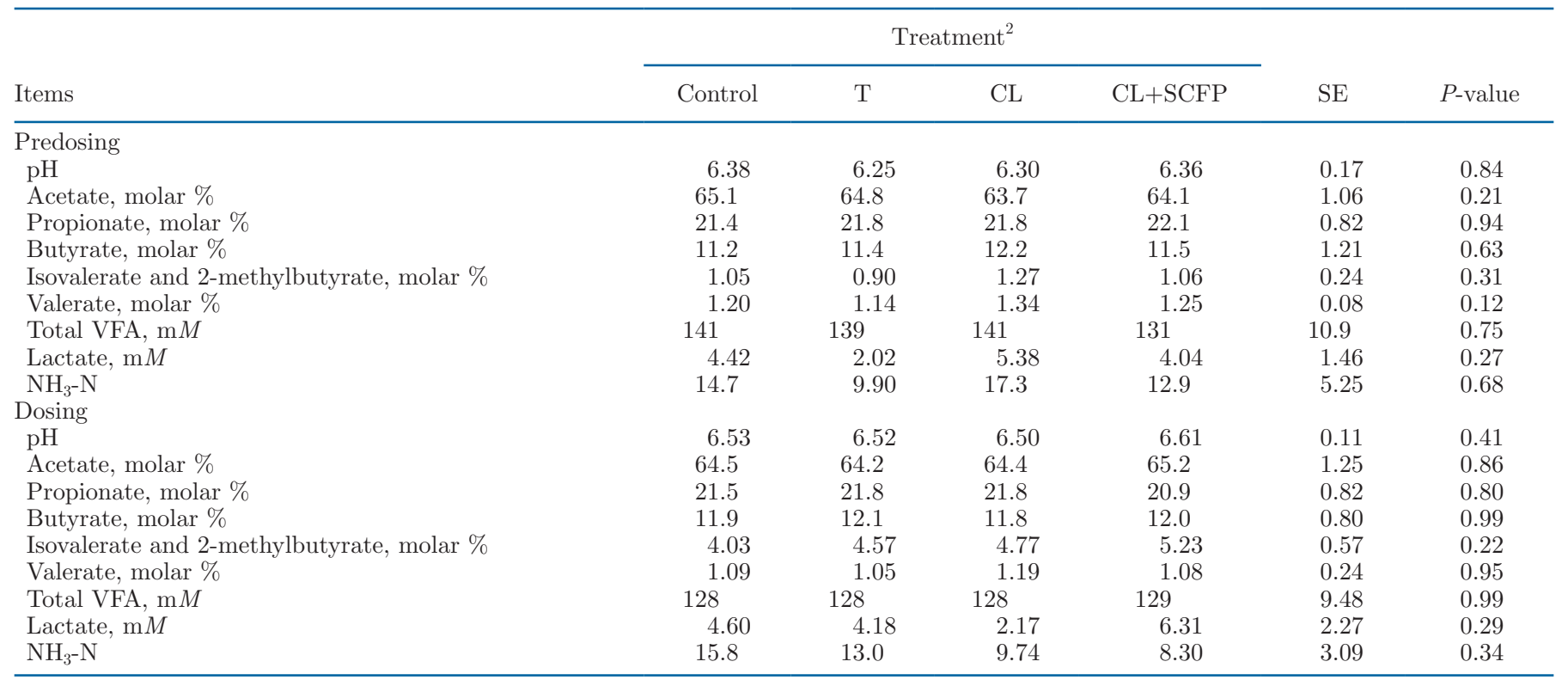

${ }^{1}$ Saccharomyces cerevisiae fermentation product-based sequestering agent (Diamond V Inc., Cedar Rapids, IA).

${ }^{2} \mathrm{~T}=$ control diet $+\mathrm{AFB}_{1}(63.4 \mu \mathrm{g} / \mathrm{kg}$ of DMI $) ; \mathrm{CL}=\mathrm{T}+200 \mathrm{~g} / \mathrm{d}$ of bentonite clay; CL+SCFP $=\mathrm{CL}+35 \mathrm{~g} / \mathrm{d}$ of SCFP. 


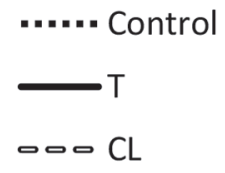

A

$-\cdot C L+S C F P$

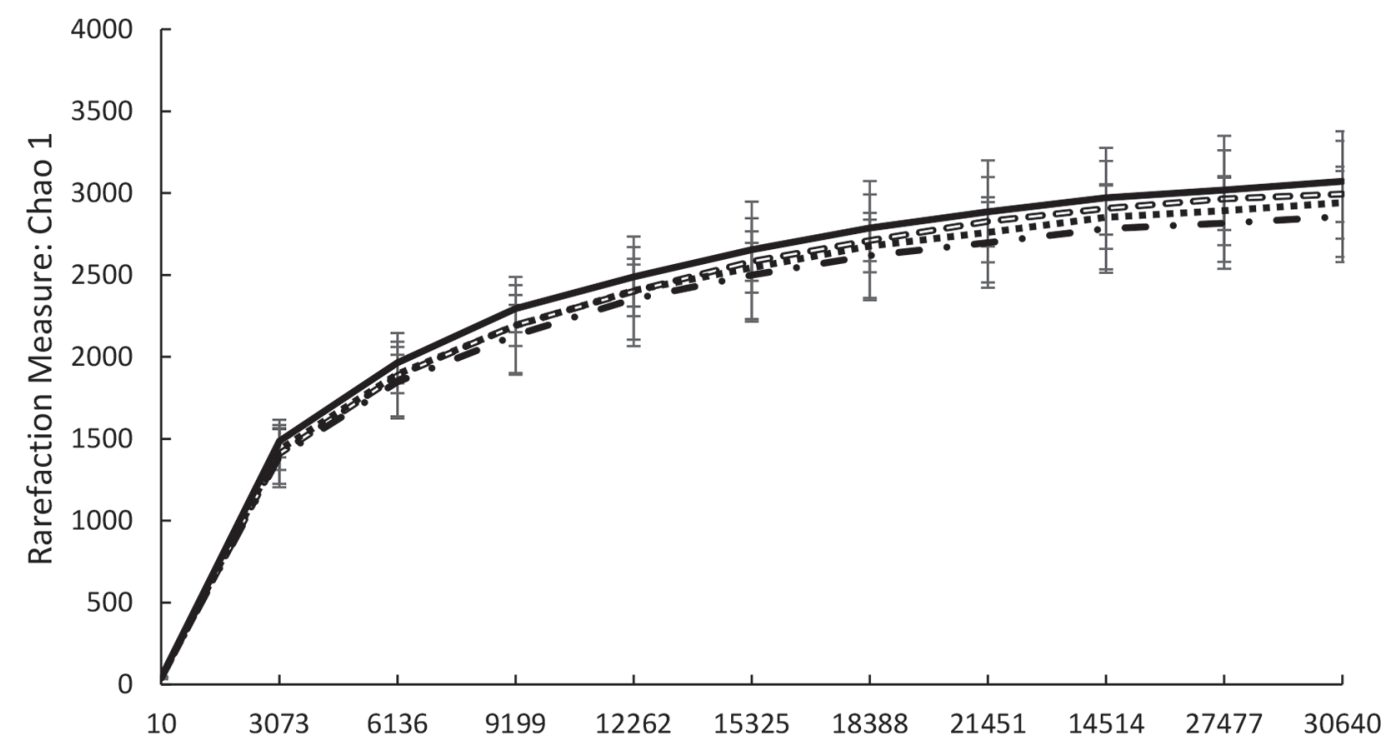

B

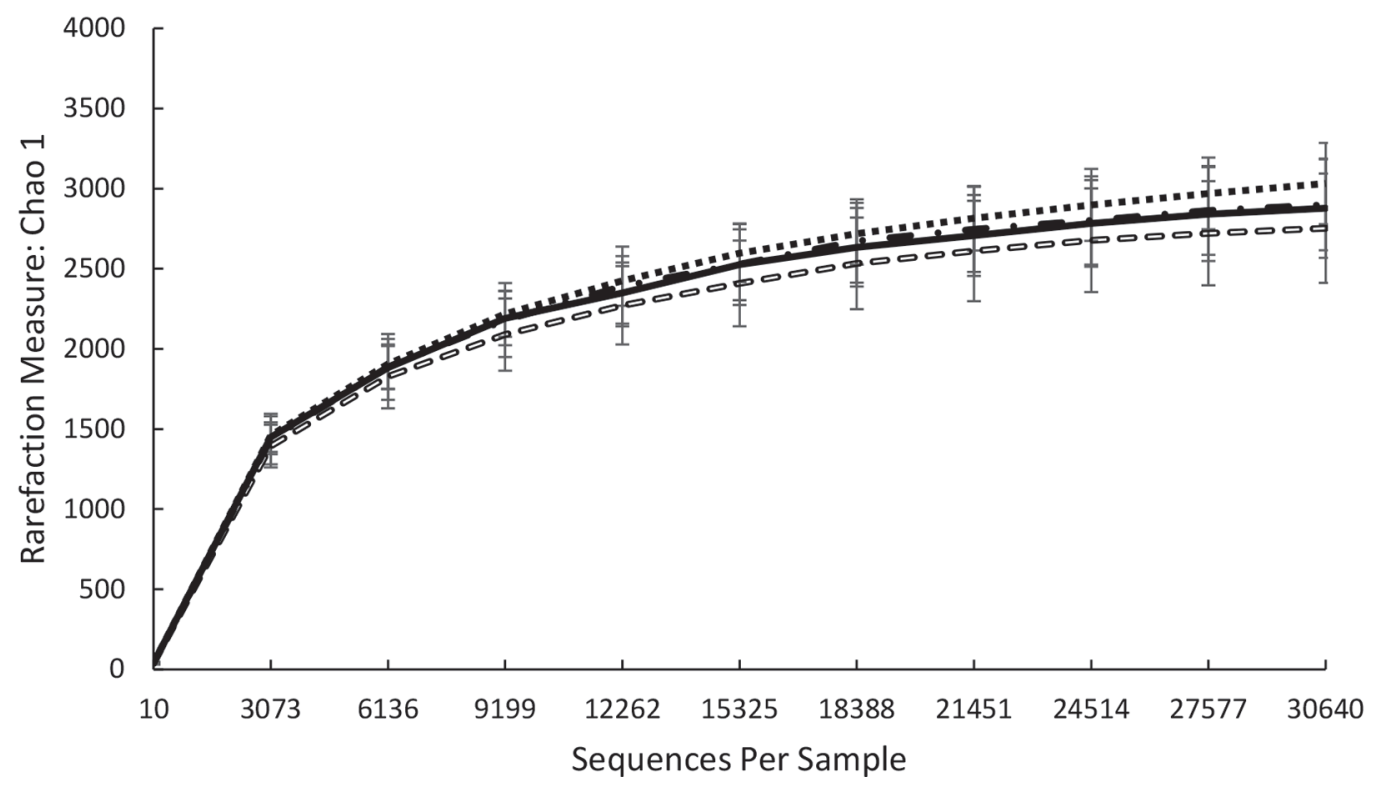

Figure 1. Species richness of bacterial communities estimated by Chao 1 index in rumen fluid of cows fed aflatoxin $\mathrm{B}_{1}\left(\mathrm{AFB}_{1}\right)$ with or without bentonite clay (CL) and Saccharomyces cerevisiae fermentation product (SCFP)-based sequestering agent (Diamond V Inc., Cedar Rapids, IA) in the (A) predosing period, and (B) dosing period. The phylogenetic diversity metric was compared across treatments at the highest rarefaction depth. No treatment effects were evident $(P>0.10)$. $\mathrm{T}=$ control diet $+\mathrm{AFB}_{1}(63.4 \mu \mathrm{g} / \mathrm{kg}$ of DMI $) ; \mathrm{CL}=\mathrm{T}+200 \mathrm{~g} / \mathrm{d}$ of bentonite clay; $\mathrm{CL}+\mathrm{SCFP}=\mathrm{CL}+35 \mathrm{~g} / \mathrm{d}$ of SCFP. Error bars indicate SD. 
bacterial genera included unclassified Clostridiales, Succiniclasticum, and unclassified Succinivibrionaceae, each accounting for about $6 \%$, and Ruminococcus, Butyrivibrio, and Fibrobacter, accounting for $3.5 \pm 1.6$, $2.0 \pm 0.72$, and $1.1 \pm 0.48 \%$ of total bacteria genera, respectively.

\section{Treatment Effects on Diversity of Dominant Bacterial Phyla}

During the predosing period, the relative abundance of Bacteroidetes in the rumen was greater $(P<0.05$, Table 2; Figure 4) in cows fed CL+SCFP compared with the control and $\mathrm{T}(55.8$ vs. 50.6 and $51.4 \%$, respectively) and tended to be greater $(P<0.10)$ in cows fed CL compared with T (55.1 vs. $51.4 \%)$. In the dosing period, feeding $\mathrm{T}$ did not affect $(P>0.10)$ the bacterial community at the phylum level. Cows fed CL+SCFP had greater relative abundance of Fibrobacteres compared with T (1.45 vs. $0.95 \%, P=0.04)$.

A

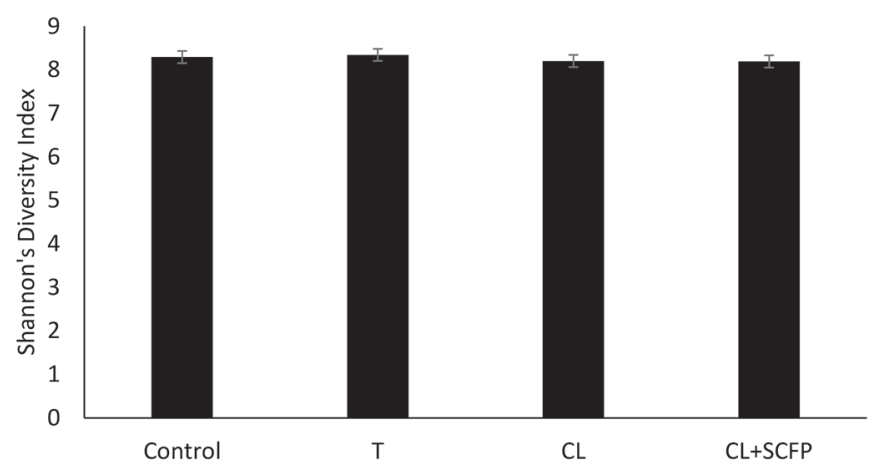

B

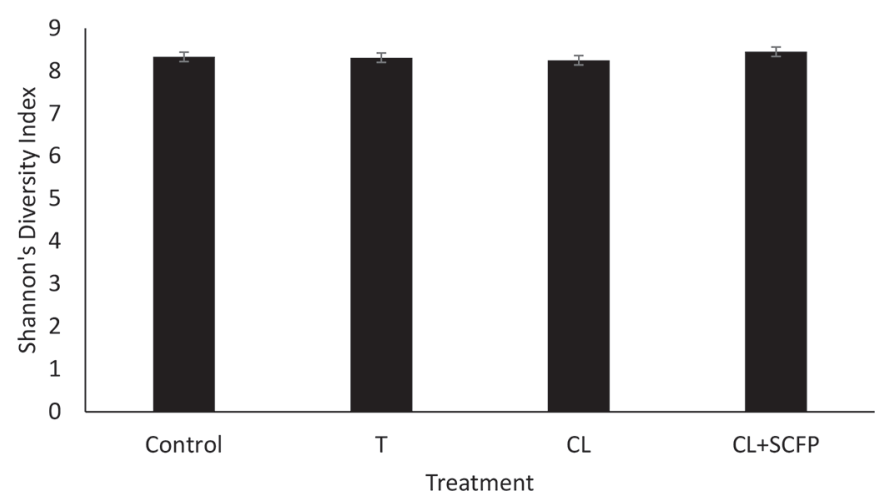

Figure 2. Phylogenetic diversity of bacterial communities estimated by Shannon's index in rumen fluid of cows fed aflatoxin $\mathrm{B}_{1}\left(\mathrm{AFB}_{1}\right)$ with or without bentonite clay (CL) and Saccharomyces cerevisiae fermentation product (SCFP)-based sequestering agent (Diamond V Inc., Cedar Rapids, IA) in the (A) predosing period $(P=0.83)$, and (B) dosing period $(P=0.56)$. $\mathrm{T}=$ control diet $+\mathrm{AFB}_{1}(63.4 \mu \mathrm{g} / \mathrm{kg}$ of DMI); $\mathrm{CL}=\mathrm{T}+200 \mathrm{~g} / \mathrm{d}$ of bentonite clay; $\mathrm{CL}+\mathrm{SCFP}=\mathrm{CL}+35$ $\mathrm{g} / \mathrm{d}$ of SCFP. Error bars indicate SD.
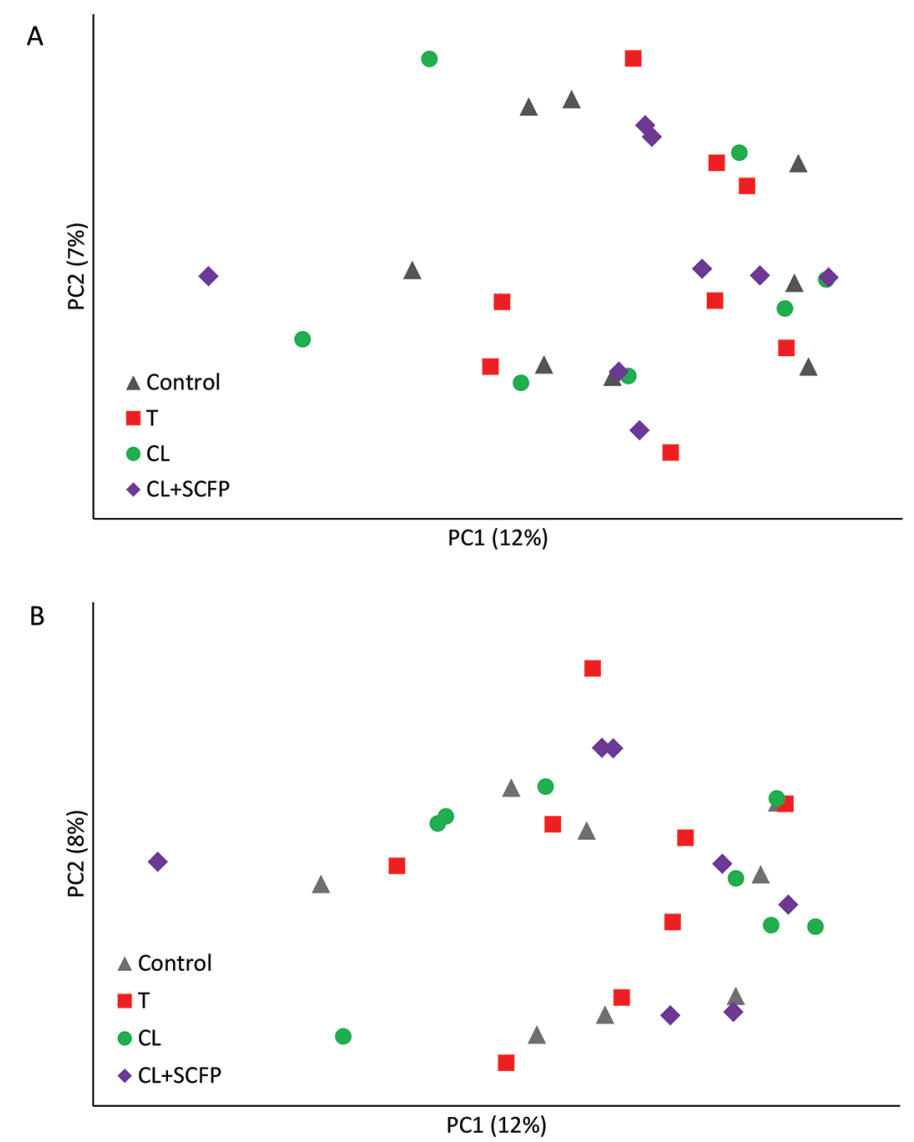

Figure 3. Unweighted UniFrac principal coordinate (PC) analysis plot of $\beta$ diversity of ruminal samples from cows fed aflatoxin $\mathrm{B}_{1}\left(\mathrm{AFB}_{1}\right)$ with or without bentonite clay $(\mathrm{CL})$ and Saccharomyces cerevisiae fermentation product (SCFP)-based sequestering agent (Diamond V Inc., Cedar Rapids, IA) in the $(\mathrm{A})$ predosing period $(P$ $=0.90)$, and $(\mathrm{B})$ dosing period $(P=0.99) . \mathrm{T}=$ control diet $+\mathrm{AFB}_{1}$ $(63.4 \mu \mathrm{g} / \mathrm{kg}$ of DMI $) ; \mathrm{CL}=\mathrm{T}+200 \mathrm{~g} / \mathrm{d}$ of bentonite clay; $\mathrm{CL}+\mathrm{SCFP}$ $=\mathrm{CL}+35 \mathrm{~g} / \mathrm{d}$ of SCFP.

\section{Treatment Effects on Diversity of Dominant Bacterial Families}

During the predosing period, the relative abundance of Prevotellaceae was higher $(P=0.05)$ with CL+SCFP compared with the control (43.6 vs. $40.0 \%$, Table 3; Figure 4). Similarly, Paraprevotellaceae tended to be more abundant with CL+SCFP compared with the control (6.03 vs. $5.06 \%, P=0.09$, respectively). The relative abundance of unclassified Clostridiales was lower (5.24 vs. $6.38 \%, P=0.02$ ) or tended to be lower (5.24 vs. $6.04 \% P=0.08)$ in cows fed CL+SCFP relative to CL or the control, respectively. The relative abundance of Lachnospiraceae also tended to be lower in CL+SCFP compared with the control and T (5.06 vs. 6.43 and 6.45 , respectively; $P=0.06$ ).

During the dosing period, feeding $\mathrm{T}$ did not affect $(P>0.10)$ the bacterial abundances at the family 
Table 2. Effects of dosing aflatoxin $\mathrm{B}_{1}\left(\mathrm{AFB}_{1}\right)$ with or without clay $(\mathrm{CL})$ and Saccharomyces cerevisiae fermentation product $(\mathrm{SCFP})^{1}$ on the relative abundance of dominant bacteria phyla $(>0.5 \%)$ in the rumen during the predosing and dosing periods

\begin{tabular}{|c|c|c|c|c|c|c|}
\hline \multirow[b]{2}{*}{ Phylum } & \multicolumn{4}{|c|}{ Treatment $^{2}$} & \multirow[b]{2}{*}{ SEM } & \multirow[b]{2}{*}{$P$-value } \\
\hline & Control & $\mathrm{T}$ & CL & $\mathrm{CL}+\mathrm{SCFP}$ & & \\
\hline \multicolumn{7}{|l|}{ Predosing } \\
\hline Bacteroidetes & $50.6^{\mathrm{c}, \mathrm{xy}}$ & $51.4^{\mathrm{bc}, \mathrm{y}}$ & $55.1^{\mathrm{ab}, \mathrm{x}}$ & $55.8^{\mathrm{a}, \mathrm{xy}}$ & 1.55 & 0.01 \\
\hline Firmicutes & 29.1 & 29.8 & 27.3 & 26.0 & 1.37 & 0.17 \\
\hline Proteobacteria & 7.18 & 6.28 & 5.74 & 6.78 & 1.47 & 0.90 \\
\hline Euryarchaeota & 2.78 & 2.94 & 3.04 & 2.41 & 0.35 & 0.35 \\
\hline Spirochaetes & 1.82 & 1.75 & 1.81 & 1.59 & 0.24 & 0.84 \\
\hline Cyanobacteria & 1.57 & 1.06 & 0.81 & 1.32 & 0.22 & 0.20 \\
\hline Actinobacteria & 1.27 & 1.33 & 1.10 & 0.89 & 0.43 & 0.38 \\
\hline Fibrobacteres & 1.04 & 1.05 & 1.07 & 1.09 & 0.19 & 0.99 \\
\hline SR1 & 1.20 & 0.97 & 0.71 & 0.95 & 0.26 & 0.65 \\
\hline Tenericutes & 0.61 & 0.70 & 0.58 & 0.46 & 0.08 & 0.16 \\
\hline Verrucomicrobia & 0.57 & 0.67 & 0.77 & 0.67 & 0.13 & 0.66 \\
\hline \multicolumn{7}{|l|}{ Dosing } \\
\hline Bacteroidetes & 49.6 & 52.6 & 51.3 & 51.1 & 2.59 & 0.79 \\
\hline Firmicutes & 30.7 & 28.5 & 27.3 & 28.2 & 1.62 & 0.52 \\
\hline Proteobacteria & 6.71 & 5.76 & 8.22 & 5.71 & 1.27 & 0.49 \\
\hline Euryarchaeota & 3.21 & 3.64 & 3.42 & 3.76 & 0.40 & 0.48 \\
\hline Spirochaetes & 1.78 & 1.62 & 1.95 & 2.38 & 0.34 & 0.13 \\
\hline Cyanobacteria & 0.98 & 1.15 & 1.09 & 1.34 & 0.17 & 0.46 \\
\hline Actinobacteria & 1.01 & 1.25 & 1.12 & 0.91 & 0.32 & 0.58 \\
\hline Fibrobacteres & $1.05^{\mathrm{ab}}$ & $0.97^{\mathrm{b}}$ & $1.08^{\mathrm{ab}}$ & $1.45^{\mathrm{a}}$ & 0.14 & 0.04 \\
\hline SR1 & 1.28 & 0.99 & 1.00 & 1.31 & 0.14 & 0.18 \\
\hline Tenericutes & 0.70 & 0.77 & 0.90 & 0.65 & 0.12 & 0.35 \\
\hline Verrucomicrobia & 0.63 & 0.73 & 0.56 & 0.74 & 0.18 & 0.72 \\
\hline
\end{tabular}

${ }^{\mathrm{a}-\mathrm{c}}$ Means within a row with no common superscripts differ $(P \leq 0.05)$.

${ }^{\mathrm{x}, \mathrm{y}}$ Means within a row with no common superscripts tend to differ $(0.05<P \leq 0.10)$.

${ }^{1}$ Saccharomyces cerevisiae fermentation product-based sequestering agent (Diamond V Inc., Cedar Rapids, IA).

${ }^{2} \mathrm{~T}=$ control diet $+\mathrm{AFB}_{1}(63.4 \mu \mathrm{g} / \mathrm{kg}$ of DMI $) ; \mathrm{CL}=\mathrm{T}+200 \mathrm{~g} / \mathrm{d}$ of bentonite clay; $\mathrm{CL}+\mathrm{SCFP}=\mathrm{CL}+35$ $\mathrm{g} / \mathrm{d}$ of SCFP.

level compared with the control (Table 3). The relative abundance of Fibrobacteraceae was greater (1.45 vs. 0.97, $P=0.04)$ with CL+SCFP compared with T and tended to be greater (1.45 vs. $1.05, P=0.09$ ) compared with the control.

\section{Treatment Effects on Diversity of Dominant Bacterial Genera}

During the predosing period, the relative abundance of Prevotella tended to be greater (43.6 vs. 40.0, $P=$ 0.09; Table 4; Figure 4) with CL+SCFP compared with the control. The relative abundance of unclassified Clostridiales was lower (6.38 vs. 5.24, $P=0.02)$ with $\mathrm{CL}+\mathrm{SCFP}$ compared with CL. The relative abundance of Butyrivibrio was lower (1.41 vs. 1.92 and 2.07, respectively; $P=0.01)$ with $\mathrm{CL}+\mathrm{SCFP}$ compared with the control and $\mathrm{T}$.

During the dosing period, the relative abundance of Butyrivibrio was lower (1.93 and 1.86 vs. 2.57, respectively, $P=0.02$; Table 5 ) in cows fed CL and $\mathrm{CL}+\mathrm{SCFP}$ compared with $\mathrm{T}$. The relative abundance of Fibrobacter was greater or tended to be greater with CL+SCFP compared with T (1.45 vs. $0.97, P=0.04)$ or the control (1.45 vs. $1.05, P=0.10)$, respectively.

\section{Correlation Between Bacterial Abundance and Dairy Cow Performance}

The heatmap showing the Pearson correlation coefficients between dairy cow performance measurements and relative abundances of dominant bacterial genera is presented in Figure 5. Dry matter intake was positively correlated with relative abundances of unclassified Succinivibrionaceae $(\mathrm{r}=0.63 ; P<0.01)$ and Coprococcus $(\mathrm{r}=0.61 ; P<0.01)$ and negatively correlated with the relative abundance of Succiniclasticum $(\mathrm{r}=-0.49, P<$ 0.01), unclassified Bacteroidales $(\mathrm{r}=-0.41, P<0.01$ ), unclassified Ruminococcaceae ( $\mathrm{r}=-0.46, P<0.01)$, Methanobrevibacter $(\mathrm{r}=0.50, P<0.01)$, Butyrivibrio $(\mathrm{r}$ $=-0.38, P<0.01)$, CF231 $(\mathrm{r}=-0.59, P<0.01)$, and unclassified Paraprevotellaceae $(\mathrm{r}=-0.33, P=0.03)$. Milk yield was positively correlated with the relative abundance of Succinivibrionaceae $(\mathrm{r}=0.62, P<0.01)$, 
A

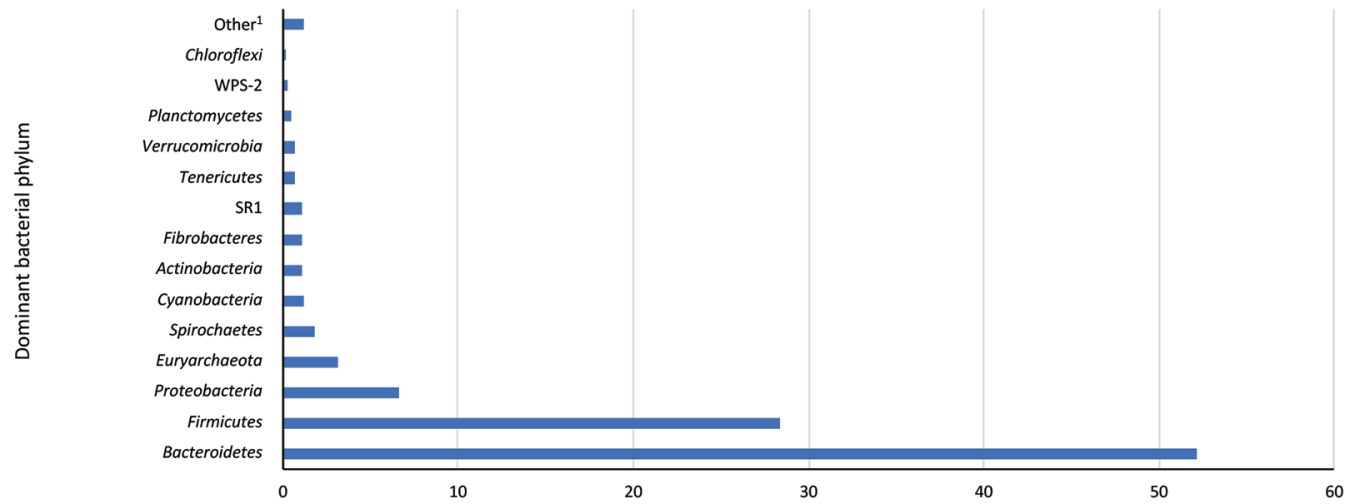

B

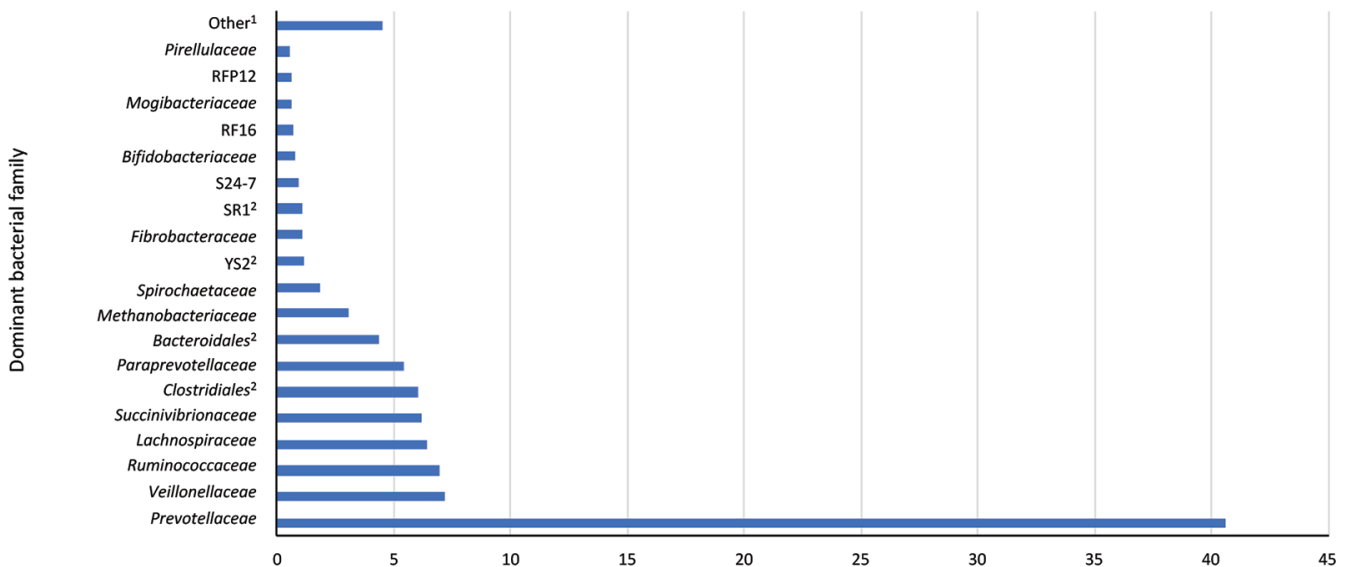

C

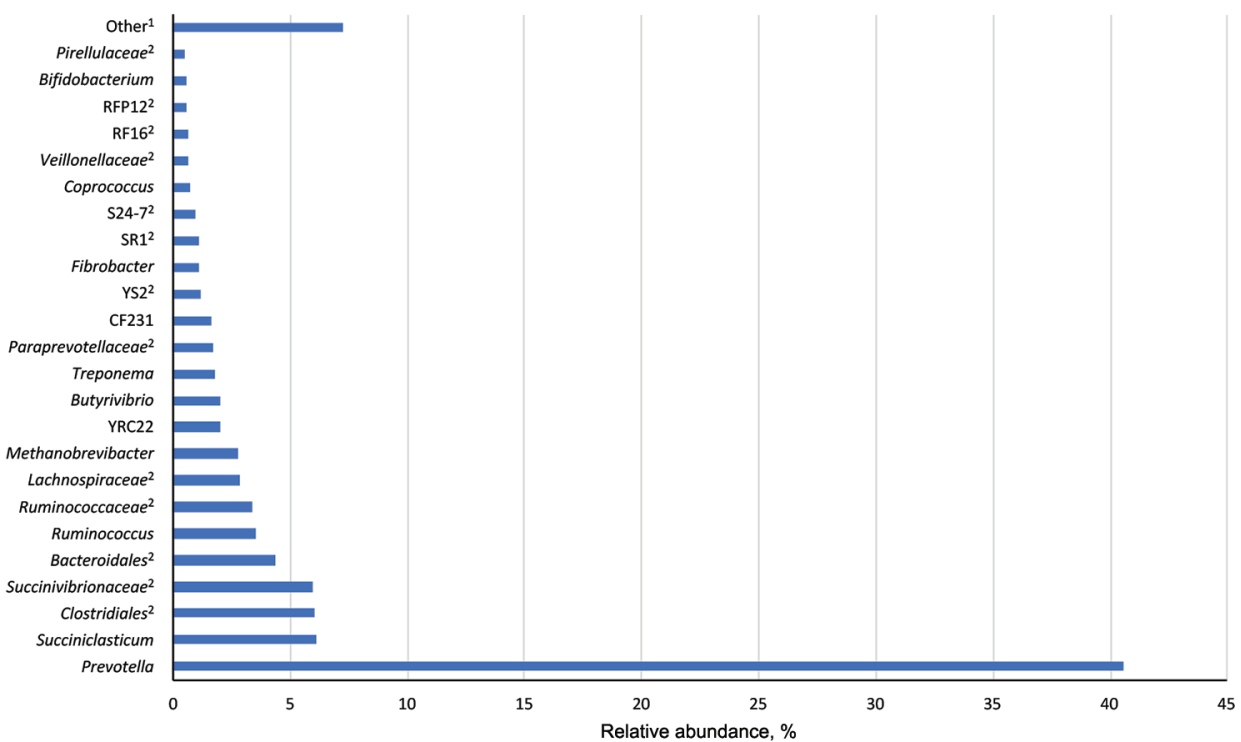

Figure 4. Relative abundance (\%) of the dominant bacterial (A) phyla, (B) families, and (C) genera in the rumen of dairy cows as analyzed by MiSeq 16S rRNA gene sequencing. Footnote 1 indicates less abundant and unassigned taxa; footnote 2 indicates unknown members within the respective taxa. 
YS2 $(\mathrm{r}=0.34, P=0.02)$, and Coprococcus $(\mathrm{r}=0.66, P$ $<0.01$ ) and negatively correlated with Succiniclasticum $(\mathrm{r}=-0.56, P<0.01)$, unclassified Bacteroidales $(\mathrm{r}=$ $-0.45, P<0.01$ ), unclassified Ruminococcaceae ( $\mathrm{r}=$ $-0.45, P<0.01)$, Methanobrevibacter $(\mathrm{r}=-0.33, P$ $=0.03)$, Butyrivibrio $(\mathrm{r}=-0.31, P=0.04), \mathrm{CF} 231$ $(\mathrm{r}=-0.67, P<0.01)$, and unclassified Paraprevotellaceae $(\mathrm{r}=-0.40, P<0.01)$. The yield of $3.5 \% \mathrm{FCM}$ was positively correlated with the relative abundance of unclassified Succinivibrionaceae $(\mathrm{r}=0.49, P<0.01)$, unclassified YS2 $(\mathrm{r}=0.40, P<0.01)$, and Coprococcus $(\mathrm{r}=0.63, P<0.01)$ and negatively correlated with that of Succiniclasticum $(\mathrm{r}=-0.53, P<0.01)$, unclassified Bacteroidales $(\mathrm{r}=-0.34, P=0.02)$, unclassified Ruminococcaceae $(\mathrm{r}=-0.32), \mathrm{CF} 231(\mathrm{r}=-0.58)$, and unclassified Paraprevotellaceae $(\mathrm{r}=-0.31, P=0.04)$. In addition, a relatively precise linear relationship was detected between the abundance of Coprococcus and DMI $\left(\mathrm{R}^{2}=0.37, P<0.0001\right.$, Figure $\left.6 \mathrm{~A}\right)$, milk yield $\left(\mathrm{R}^{2}\right.$
$=0.43, P<0.0001$, Figure $6 \mathrm{~B})$, and feed efficiency $\left(\mathrm{R}^{2}\right.$ $=0.09, P=0.06$, Figure $6 \mathrm{C}$ ).

Milk fat yield was positively correlated with relative abundances of unclassified Succinivibrionaceae (r $=0.42, P<0.01)$, Treponema $(\mathrm{r}=0.34, P=0.02)$, YS2 ( $\mathrm{r}=0.42, P<0.01)$, and Coprococcus $(\mathrm{r}=0.56$, $P<0.01)$ and negatively correlated with the relative abundance of Succiniclasticum $(\mathrm{r}=-0.43, P<0.01)$ and CF231 ( $\mathrm{r}=-0.52, P<0.01)$. Milk protein yield was positively correlated with the relative abundance of unclassified Succinivibrionaceae $(\mathrm{r}=0.55, P<0.01)$ and Coprococcus $(\mathrm{r}=0.60, P<0.01)$ and negatively correlated with the relative abundance of Succiniclasticum $(\mathrm{r}=-0.53, P<0.01)$, unclassified Bacteroidales $(\mathrm{r}=-0.40, P<0.01)$, unclassified Ruminococcaceae $(\mathrm{r}=-0.40, P<0.01)$, Butyrivibrio $(\mathrm{r}=-0.30, P=$ $0.05), \mathrm{CF} 231(\mathrm{r}=-0.59, P<0.01)$, and unclassified Paraprevotellaceae $(\mathrm{r}=-0.38, P<0.01)$. Milk lactose yield was positively correlated with relative abundance

Table 3. Effects of dosing aflatoxin $\mathrm{B}_{1}\left(\mathrm{AFB}_{1}\right)$ with or without clay $(\mathrm{CL})$ and Saccharomyces cerevisiae fermentation product $(\mathrm{SCFP})^{1}$ on the relative abundance of rumen bacteria families $(>1 \%)$ in the rumen during the predosing and dosing periods

\begin{tabular}{|c|c|c|c|c|c|c|}
\hline \multirow[b]{2}{*}{ Family } & \multicolumn{4}{|c|}{ Treatment $^{2}$} & \multirow[b]{2}{*}{ SEM } & \multirow[b]{2}{*}{$P$-value } \\
\hline & Control & $\mathrm{T}$ & CL & $\mathrm{CL}+\mathrm{SCFP}$ & & \\
\hline \multicolumn{7}{|l|}{ Predosing } \\
\hline Prevotellaceae & $40.0^{\mathrm{b}}$ & $40.3^{\mathrm{ab}}$ & $43.3^{\mathrm{ab}}$ & $43.6^{\mathrm{a}}$ & 1.45 & 0.05 \\
\hline Ruminococcaceae & 7.55 & 7.92 & 6.08 & 6.98 & 0.70 & 0.28 \\
\hline Veillonellaceae & 7.38 & 7.61 & 6.87 & 7.02 & 0.72 & 0.77 \\
\hline Clostridiales $^{3}$ & $6.04^{\mathrm{ab}, \mathrm{x}}$ & $6.18^{\mathrm{a}, \mathrm{xy}}$ & $6.38^{\mathrm{a}, \mathrm{xy}}$ & $5.24^{\mathrm{b}, \mathrm{y}}$ & 0.36 & 0.02 \\
\hline Lachnospiraceae & $6.43^{\mathrm{x}}$ & $6.45^{\mathrm{x}}$ & $6.22^{\mathrm{xy}}$ & $5.06^{\mathrm{y}}$ & 0.57 & 0.06 \\
\hline Succinivibrionaceae & 6.73 & 5.85 & 5.23 & 6.13 & 1.51 & 0.90 \\
\hline Paraprevotellaceae & $5.06^{\mathrm{y}}$ & $5.39^{\mathrm{xy}}$ & $5.65^{\mathrm{xy}}$ & $6.03^{\mathrm{x}}$ & 0.39 & 0.09 \\
\hline Bacteroidales ${ }^{3}$ & 3.97 & 4.07 & 4.00 & 4.49 & 0.61 & 0.78 \\
\hline Methanobacteriaceae & 2.73 & 2.90 & 2.99 & 2.36 & 0.34 & 0.34 \\
\hline Spirochaetaceae & 1.82 & 1.75 & 1.80 & 1.58 & 0.26 & 0.84 \\
\hline $\mathrm{YS}^{3}$ & 1.55 & 1.05 & 0.80 & 1.30 & 9.26 & 0.20 \\
\hline Fibrobacteraceae & 1.04 & 1.05 & 1.07 & 1.09 & 0.19 & 0.99 \\
\hline $\mathrm{SR}^{3}$ & 1.20 & 0.97 & 0.71 & 0.95 & 0.26 & 0.65 \\
\hline \multicolumn{7}{|l|}{ Dosing } \\
\hline Prevotellaceae & 39.2 & 41.2 & 39.0 & 38.4 & 2.57 & 0.76 \\
\hline Ruminococcaceae & 7.65 & 6.19 & 6.19 & 6.85 & 0.73 & 0.24 \\
\hline Veillonellaceae & 7.51 & 7.03 & 7.15 & 6.78 & 0.84 & 0.92 \\
\hline Clostridiales $^{3}$ & 6.52 & 6.35 & 5.87 & 5.77 & 0.50 & 0.62 \\
\hline Lachnospiraceae & 7.04 & 7.22 & 6.35 & 6.15 & 0.46 & 0.31 \\
\hline Succinivibrionaceae & 6.33 & 5.32 & 7.77 & 5.39 & 1.53 & 0.57 \\
\hline Paraprevotellaceae & 4.83 & 5.30 & 5.63 & 5.70 & 0.42 & 0.13 \\
\hline Bacteroidales $^{3}$ & 4.03 & 4.57 & 4.77 & 5.30 & 0.60 & 0.23 \\
\hline Methanobacteriaceae & 3.17 & 3.61 & 3.36 & 3.69 & 0.40 & 0.50 \\
\hline Spirochaetaceae & 1.78 & 1.62 & 1.95 & 2.30 & 0.37 & 0.37 \\
\hline $\mathrm{YS}^{3}$ & 0.96 & 1.13 & 1.06 & 1.30 & 0.16 & 0.40 \\
\hline Fibrobacteraceae & $1.05^{\mathrm{ab}, \mathrm{y}}$ & $0.97^{\mathrm{b}, \mathrm{y}}$ & $1.08^{\mathrm{ab}, \mathrm{xy}}$ & $1.45^{\mathrm{a}, \mathrm{x}}$ & 0.14 & 0.04 \\
\hline $\mathrm{SR} 1^{3}$ & 1.28 & 0.99 & 1.00 & 1.31 & 0.14 & 0.18 \\
\hline
\end{tabular}

$\overline{\mathrm{a}, \mathrm{b}}$ Means within a row with no common superscripts differ $(P \leq 0.05)$.

${ }^{\mathrm{x}, \mathrm{y}}$ Means within a row with no common superscripts tend to differ $(0.05<P \leq 0.10)$.

${ }^{1}$ Saccharomyces cerevisiae fermentation product-based sequestering agent (Diamond V Inc., Cedar Rapids, IA).

${ }^{2} \mathrm{~T}=$ control diet $+\mathrm{AFB}_{1}(63.4 \mu \mathrm{g} / \mathrm{kg}$ of DMI $) ; \mathrm{CL}=\mathrm{T}+200 \mathrm{~g} / \mathrm{d}$ of bentonite clay; $\mathrm{CL}+\mathrm{SCFP}=\mathrm{CL}+35$ $\mathrm{g} / \mathrm{d}$ of SCFP.

${ }^{3}$ Unclassified members in the respective taxon. 
Table 4. Effects of dosing aflatoxin $\mathrm{B}_{1}\left(\mathrm{AFB}_{1}\right)$ with or without clay (CL) and Saccharomyces cerevisiae fermentation product $(\mathrm{SCFP})^{1}$ on the relative abundance of dominant rumen bacteria genera $(>0.5 \%)$ in the rumen during the predosing period

\begin{tabular}{|c|c|c|c|c|c|c|}
\hline \multirow[b]{2}{*}{ Genus } & \multicolumn{4}{|c|}{ Treatment $^{2}$} & \multirow[b]{2}{*}{ SEM } & \multirow[b]{2}{*}{$P$-value } \\
\hline & Control & $\mathrm{T}$ & CL & $\mathrm{CL}+\mathrm{SCFP}$ & & \\
\hline Prevotella & $40.0^{\mathrm{b}}$ & $40.3^{\mathrm{ab}}$ & $43.3^{\mathrm{ab}}$ & $43.6^{\mathrm{a}}$ & 1.45 & 0.05 \\
\hline Clostridiales $^{3}$ & $6.04^{\mathrm{ab}}$ & $6.18^{\mathrm{a}}$ & $6.38^{\mathrm{a}}$ & $5.24^{\mathrm{b}}$ & 0.33 & 0.02 \\
\hline Succiniclasticum & 5.24 & 6.75 & 5.51 & 6.01 & 0.70 & 0.35 \\
\hline Succinivibrionaceae $e^{3}$ & 6.52 & 5.53 & 5.05 & 5.92 & 1.52 & 0.90 \\
\hline Bacteroidales $^{3}$ & 3.97 & 4.07 & 4.00 & 4.49 & 0.61 & 0.78 \\
\hline Ruminococcaceae $e^{3}$ & 3.42 & 3.42 & 3.14 & 3.23 & 0.33 & 0.71 \\
\hline Ruminococcus & 4.06 & 4.45 & 3.01 & 3.68 & 0.61 & 0.37 \\
\hline Lachnospiraceae ${ }^{3}$ & 2.83 & 2.82 & 2.80 & 2.37 & 0.27 & 0.33 \\
\hline Methanobrevibacter & 2.45 & 2.63 & 2.70 & 2.17 & 0.33 & 0.31 \\
\hline YRC22 & 1.89 & 2.01 & 2.32 & 2.34 & 0.25 & 0.39 \\
\hline Butyrivibrio & $1.92^{\mathrm{a}}$ & $2.07^{\mathrm{a}}$ & $1.79^{\mathrm{ab}}$ & $1.41^{\mathrm{b}}$ & 0.20 & 0.01 \\
\hline Treponema & 1.81 & 1.75 & 1.80 & 1.58 & 0.24 & 0.84 \\
\hline CF231 & 1.53 & 1.63 & 1.66 & 1.89 & 0.15 & 0.18 \\
\hline Paraprevotellaceae ${ }^{3}$ & 1.60 & 1.72 & 1.57 & 1.74 & 0.21 & 0.78 \\
\hline $\mathrm{YS}^{3}$ & 1.55 & 1.05 & 0.80 & 1.30 & 0.26 & 0.20 \\
\hline Fibrobacter & 1.04 & 1.05 & 1.07 & 1.09 & 0.19 & 0.99 \\
\hline $\mathrm{SR} 1^{3}$ & 1.20 & 0.97 & 0.71 & 0.95 & 0.26 & 0.65 \\
\hline $\mathrm{S} 24-7^{3}$ & 0.81 & 0.86 & 1.14 & 0.86 & 0.15 & 0.17 \\
\hline Coprococcus & 0.85 & 0.82 & 0.70 & 0.61 & 0.10 & 0.09 \\
\hline
\end{tabular}

$\overline{\mathrm{a}, \mathrm{b}}$ Means within a row with no common superscripts differ $(P \leq 0.05)$.

${ }^{1}$ Saccharomyces cerevisiae fermentation product-based sequestering agent (Diamond V Inc., Cedar Rapids, IA).

${ }^{2} \mathrm{~T}=$ control diet $+\mathrm{AFB}_{1}(63.4 \mu \mathrm{g} / \mathrm{kg}$ of DMI $) ; \mathrm{CL}=\mathrm{T}+200 \mathrm{~g} / \mathrm{d}$ of bentonite clay; $\mathrm{CL}+\mathrm{SCFP}=\mathrm{CL}+35$ $\mathrm{g} / \mathrm{d}$ of SCFP.

${ }^{3}$ Unclassified members in the respective taxon.

Table 5. Effects of dosing aflatoxin $\mathrm{B}_{1}\left(\mathrm{AFB}_{1}\right)$ with or without clay $(\mathrm{CL})$ and Saccharomyces cerevisiae fermentation product $(\mathrm{SCFP})^{1}$ on the relative abundance of dominant rumen bacteria genera $(>0.5 \%)$ in the rumen during the dosing period

\begin{tabular}{|c|c|c|c|c|c|c|}
\hline \multirow[b]{2}{*}{ Genus } & \multicolumn{4}{|c|}{ Treatment $^{2}$} & \multirow[b]{2}{*}{ SEM } & \multirow[b]{2}{*}{$P$-value } \\
\hline & Control & $\mathrm{T}$ & CL & $\mathrm{CL}+\mathrm{SCFP}$ & & \\
\hline Prevotella & 39.2 & 41.2 & 39.0 & 38.4 & 2.57 & 0.76 \\
\hline Clostridiales ${ }^{3}$ & 6.52 & 6.35 & 5.87 & 5.77 & 0.50 & 0.62 \\
\hline Succiniclasticum & 6.66 & 6.17 & 5.82 & 5.98 & 0.88 & 0.87 \\
\hline Succinivibrionaceae ${ }^{3}$ & 6.14 & 5.18 & 7.54 & 5.02 & 1.46 & 0.51 \\
\hline Bacteroidales ${ }^{3}$ & 4.03 & 4.57 & 4.77 & 5.30 & 0.60 & 0.23 \\
\hline Ruminococcaceae $e^{3}$ & 3.79 & 3.44 & 3.22 & 3.52 & 0.36 & 0.18 \\
\hline Ruminococcus & 3.78 & 2.67 & 2.89 & 3.42 & 0.45 & 0.17 \\
\hline Lachnospiraceae $e^{3}$ & 3.04 & 3.10 & 2.83 & 2.81 & 0.27 & 0.77 \\
\hline Methanobrevibacter & 2.83 & 3.24 & 2.99 & 3.37 & 0.37 & 0.41 \\
\hline YRC22 & 1.86 & 1.94 & 1.95 & 1.93 & 0.16 & 0.92 \\
\hline Butyrivibrio & $2.28^{\mathrm{ab}}$ & $2.57^{\mathrm{a}}$ & $1.93^{\mathrm{b}}$ & $1.86^{\mathrm{b}}$ & 0.17 & 0.02 \\
\hline Treponema & 1.78 & 1.61 & 1.94 & 2.37 & 0.34 & 0.13 \\
\hline CF231 & 1.41 & 1.61 & 1.72 & 1.85 & 0.18 & 0.32 \\
\hline Paraprevotellaceae $^{3}$ & 1.50 & 1.72 & 1.91 & 1.89 & 0.27 & 0.45 \\
\hline YS2 & 0.96 & 1.13 & 1.06 & 1.30 & 0.16 & 0.40 \\
\hline Fibrobacter & $1.05^{\mathrm{ab}, \mathrm{y}}$ & $0.97^{\mathrm{b}, \mathrm{y}}$ & $1.08^{\mathrm{ab}, \mathrm{xy}}$ & $1.45^{\mathrm{a}, \mathrm{x}}$ & 0.14 & 0.04 \\
\hline $\mathrm{SR} 1^{3}$ & 1.28 & 0.99 & 1.00 & 1.31 & 0.14 & 0.18 \\
\hline $\mathrm{S} 24-7^{3}$ & 0.94 & 0.85 & 1.09 & 1.06 & 0.16 & 0.35 \\
\hline Coprococcus & 0.79 & 0.65 & 0.68 & 0.67 & 0.07 & 0.47 \\
\hline
\end{tabular}

$\overline{\mathrm{a}, \mathrm{b}}$ Means within a row with no common superscripts differ $(P \leq 0.05)$.

${ }^{x, y}$ Means within a row with no common superscripts tend to differ $(0.05<P \leq 0.10)$.

${ }^{1}$ Saccharomyces cerevisiae fermentation product-based sequestering agent (Diamond V Inc., Cedar Rapids, IA).

${ }^{2} \mathrm{~T}=$ control diet $+\mathrm{AFB}_{1}(63.4 \mu \mathrm{g} / \mathrm{kg}$ of DMI $) ; \mathrm{CL}=\mathrm{T}+200 \mathrm{~g} / \mathrm{d}$ of bentonite clay; $\mathrm{CL}+\mathrm{SCFP}=\mathrm{CL}+35$ $\mathrm{g} / \mathrm{d}$ of SCFP.

${ }^{3}$ Unclassified members in the respective taxon. 


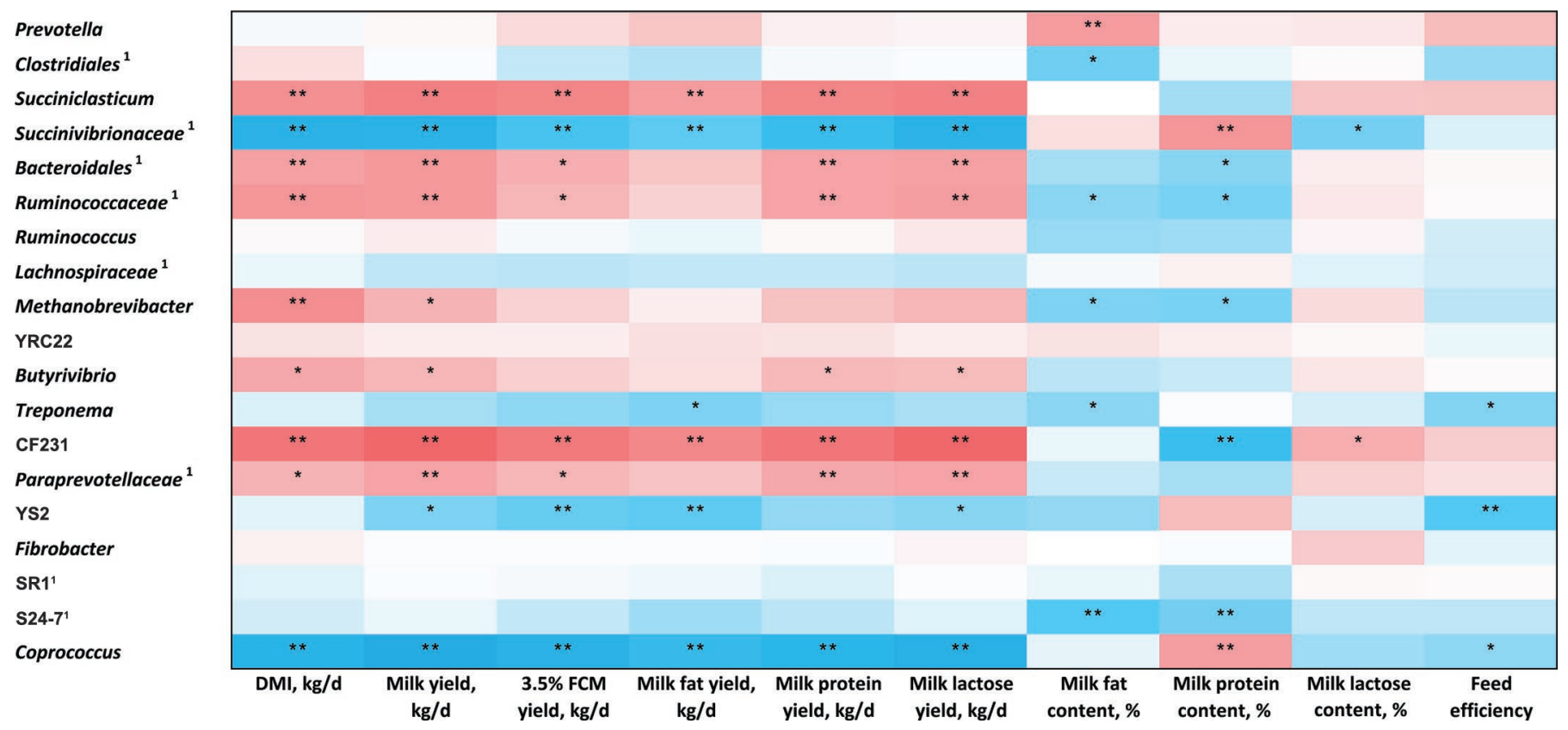

Figure 5. Pearson correlations between dairy cow performance measurements and relative abundance of dominant bacteria $(>0.5 \%$ of the bacterial population) in the rumen of dairy cows. Footnote 1 indicates classified members in the respective taxon. Significant Pearson correlation coefficient with ${ }^{*} 0.01<P \leq 0.05 ; * * \leq 0.01$. The measurements of dairy cow performance were averaged for each cow at each period. Feed efficiency was calculated by dividing $3.5 \%$ FCM by DMI.

of unclassified Succinivibrionaceae $(\mathrm{r}=0.62, P<$ $0.01)$, YS2 $(\mathrm{r}=0.32, P=0.03)$, and Coprococcus $(\mathrm{r}$ $=0.64, P<0.01)$ and negatively correlated with relative abundance of Succiniclasticum $(\mathrm{r}=-0.55, P<$ 0.01), unclassified Bacteroidales $(\mathrm{r}=-0.41, P<0.01)$, unclassified Ruminococcaceae $(\mathrm{r}=-0.42, P<0.01)$, Methanobrevibacter $(\mathrm{r}=-0.32, P=0.03), \mathrm{CF} 231(\mathrm{r}=$ $-0.67, P<0.01$ ), and unclassified Paraprevotellaceae (r $=-0.40, P<0.01)$.

Milk fat concentration was positively correlated with the relative abundance of unclassified Clostridiales ( $\mathrm{r}$ $=0.38, P=0.01)$, unclassified Ruminococcaceae $(\mathrm{r}=$ $0.31, P=0.04)$, Methanobrevibacter $(\mathrm{r}=0.34, P=$ $0.02)$, Treponema $(\mathrm{r}=0.31, P \leq 0.04)$, and S24-7 ( $\mathrm{r}$ $=0.45, P<0.01)$ and negatively correlated with the relative abundance of Prevotella $(\mathrm{r}=-0.44, P<0.01)$. Within the genus Prevotella, among the most dominant 50 OTU among over 6,000, OTU 816492 had the strongest relationship with milk fat concentration $\left(\mathrm{R}^{2}=\right.$ $0.23, P=0.001$, Figure 7 ). Milk protein was positively correlated with the relative abundance of unclassified Bacteroidales ( $\mathrm{r}=0.32, P=0.03)$, unclassified Ruminococcaceae ( $\mathrm{r}=0.35, P=0.02)$, Methanobrevibacter $(\mathrm{r}=0.35, P=0.02), \mathrm{CF} 231(\mathrm{r}=0.54, P<0.01)$, and unclassified S24-7 ( $\mathrm{r}=0.37, P=0.01)$ and negatively correlated with relative abundances of unclassified Succinivibrionaceae $(\mathrm{r}=-0.46, P<0.01)$ and Coprococcus $(\mathrm{r}=-0.42, P<0.01)$. Milk lactose concentration was positively correlated with the relative abundance of unclassified Succinivibrionaceae $(\mathrm{r}=0.36, P=0.02)$ and negatively correlated with that of unclassified SR1 $(\mathrm{r}=0.31, P=0.04)$. Feed efficiency was positively correlated with Treponema $(\mathrm{r}=0.33, P=0.03)$, unclassified YS2 $(\mathrm{r}=0.45, P<0.01)$, and Coprococcus $(\mathrm{r}=$ $0.30, P=0.05)$.

\section{DISCUSSION}

\section{Rumen Fermentation}

Our results contradict previous in vitro studies that reported impaired ruminal fermentation in presence of aflatoxin. Jiang et al. (2012) reported that 320, 640 , and $960 \mathrm{ng} / \mathrm{mL} \mathrm{AFB}_{1}$ decreased the rate of gas production and $\mathrm{NH}_{3}-\mathrm{N}$ concentration from fermentation of alfalfa and ryegrass in vitro. The high dose of $\mathrm{AFB}_{1}(960 \mathrm{ng} / \mathrm{mL})$ decreased total VFA concentration by 12.7 and $9.6 \%$ when alfalfa and ryegrass were used as substrates, respectively. Likewise, Westlake et al. (1989) and Sinha and Arora (1982) demonstrated lower in vitro DM digestion of alfalfa and cotton cellulose with aflatoxin treatment at 100 to 1,259 or 1,000 to $10,000 \mu \mathrm{g} / \mathrm{L}$, respectively. The lack of effects of $\mathrm{AFB}_{1}$ in the current study can be attributed to the differences in the experimental models used. The in vivo model used in this study allowed for rapid absorption 
A

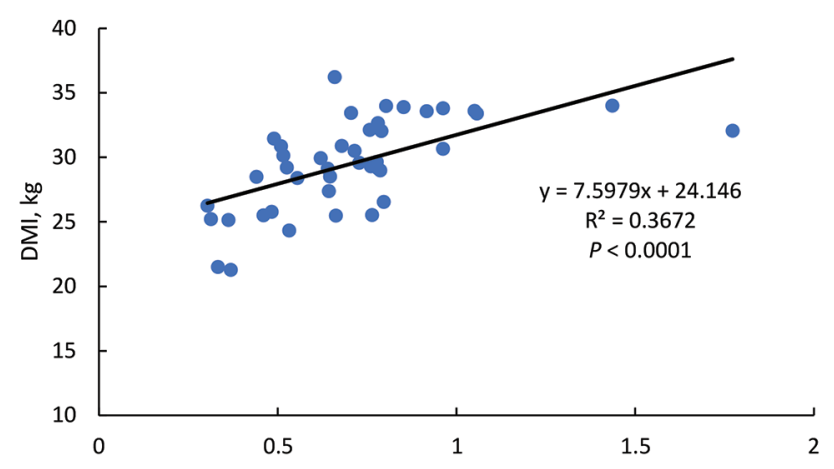

B

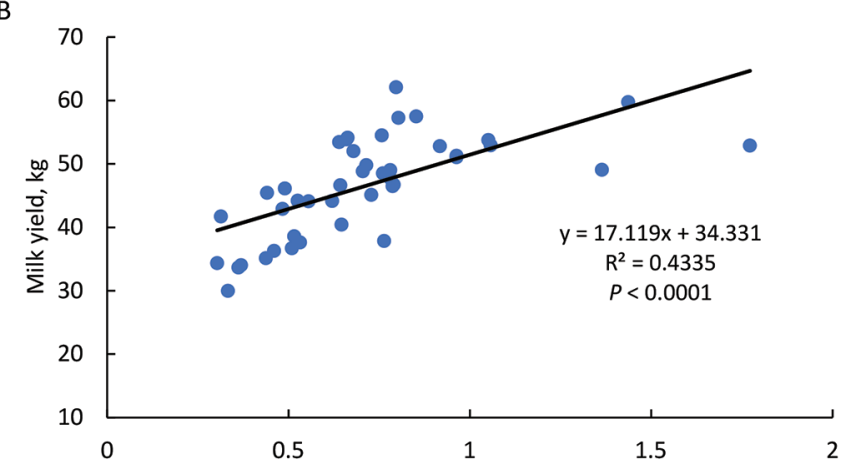

C

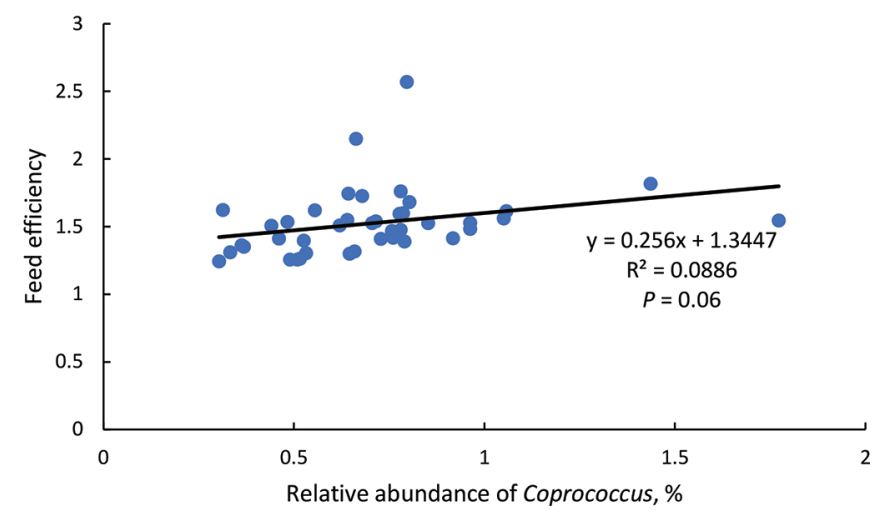

Figure 6. Relationship between the relative abundance of Coprococcus and (A) DMI, (B) milk yield, and (C) feed efficiency.

of aflatoxin in the gastrointestinal tract after dosing (Gallo et al., 2008), which was not simulated in the in vitro batch culture system used in the other studies. In addition, the previous in vitro studies used far greater doses of aflatoxin in the inoculum (320-960 $\mu \mathrm{g} / \mathrm{L}$, Jiang et al., 2012; 100-1,250 $\mu \mathrm{g} / \mathrm{L}$, Sinha and Arora, 1982; and 1,000-10,000 $\mathrm{\mu g} / \mathrm{L}$; Westlake et al., 1989) than the $63.4 \mu \mathrm{g} / \mathrm{kg} \mathrm{AFB}_{1}$ used in the current study, which should result in $<10 \mu \mathrm{g} / \mathrm{L}$ in the rumen upon ingestion, based on $27 \mathrm{~kg} / \mathrm{d} \mathrm{DMI}$ and $180 \mathrm{~L}$ of rumen volume. The $\mathrm{AFB}_{1}$ dose in our study is close to the average concentration found in an international

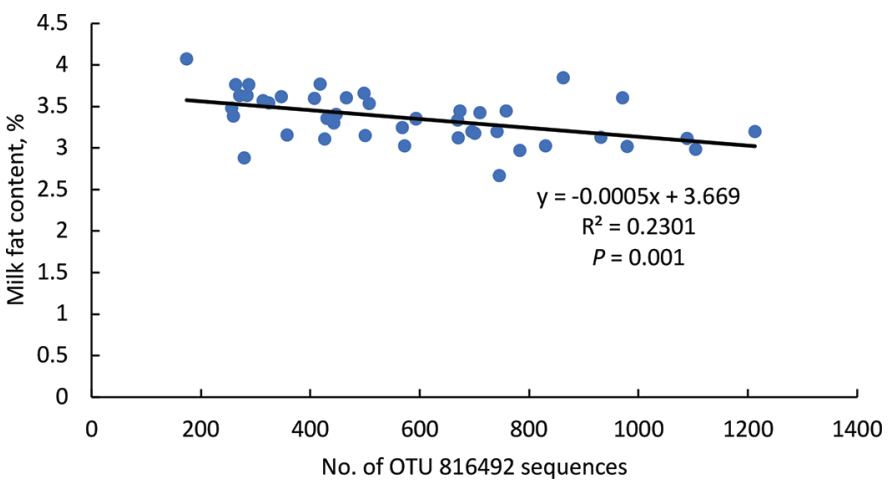

Figure 7. Relationship between the number of operational taxonomic unit (OTU) 816492 sequences and milk fat content.

survey by Rodrigues and Naehrer (2012), who reported an aflatoxin prevalence of $33 \%$ and a mean concentration of $63 \mu \mathrm{g} / \mathrm{kg}$ in more than 7,000 feed samples. The $\mathrm{AFB}_{1}$ dose in the current study is also in line with the range used in other in vivo studies $(20-112 \mu \mathrm{g} / \mathrm{kg}$; Kutz et al., 2009; Queiroz et al., 2012; Xiong et al., 2015). The effects of aflatoxin on rumen fermentation are dose dependent as observed earlier (Jiang et al., 2012), with greater doses adversely affecting ruminal fermentation. Our results indicate that consumption of $63.4 \mu \mathrm{g} / \mathrm{kg}$ aflatoxin by dairy cows had minimal effects on ruminal fermentation. Therefore, relatively low doses of aflatoxin for a short period may not adversely affect ruminal fermentation, but continuous ingestion of low doses or high doses may. Multiple samplings from the rumen rather than the single sampling used in this study may have shown effects of aflatoxin on ruminal fermentation. That approach would require cannulated animals, which could increase the risk of toxin contamination, or would require repeated stomach tubing or rumenocentesis, which could stress the cow (Cavalcanti et al., 2005) and perhaps modify the microbiome. The lack of a treatment effect on measured ruminal fermentation indices suggests that the increases in milk yield in our companion study (Jiang et al., 2018) may have been mediated by factors that were not measured, such as ruminal microbial protein synthesis, or postruminal effects, such as increased nutrient supply to the duodenum.

\section{Bacterial Diversity}

To our knowledge, no study has reported the interaction between sequestering agents, aflatoxin, and diet on the ruminal microbiome of dairy cows. In this study, the Shannon's index, which estimates phylotype richness and diversity (Hill et al., 2003), and UniFrac distance measurement, which estimates dissimilarity among the 
bacterial community of different treatments (Lozupone et al., 2011), were not affected by the dietary treatments. Wang et al. (2016) reported reduced phylogenetic diversity in response to aflatoxin consumption $\left(\mathrm{AFB}_{1}, 5-75 \mu \mathrm{g} / \mathrm{kg}\right.$ of BW) in rats; however, no studies on ruminant animals seem to be available. The lack of effects on phylogenetic diversity could be attributed to the relatively lower dose of $\mathrm{AFB}_{1}$ and rapid absorption after dosing, along with relatively low antimicrobial activity of aflatoxin (Arai et al., 1967) in the present study. Similarly, feeding CL and CL+SCFP with or without $\mathrm{T}$ had no effects on phylogenetic diversity despite reducing milk $\mathrm{AFM}_{1}$ to levels below the FDA action level (Jiang et al., 2018).

\section{Treatment Effects on Bacterial Abundance}

The most dominant phyla observed in our study were Bacteroidetes, Firmicutes, and Proteobacteria, and the results are in agreement with previous studies conducted on lactating dairy cows fed a TMR (Jami and Mizrahi, 2012; Wu et al., 2012). The most dominant bacterial families observed in our study are Prevotellaceae, Veillonellaceae, Ruminococcaceae, Lachnospiraceae, and Succinivibrionaceae, which agrees with those reported by Wu et al. (2012), who noted that Prevotella and Succiniclasticum were the most dominant genera, as also found in this study.

During the dosing period, the abundance of Bacteroidetes, Prevotellaceae, and Prevotella was not affected by supplementing with CL and CL+SCFP. Higher or numerically higher relative abundances of family $\mathrm{Fi}$ brobacteraceae and genus Fibrobacter in CL+SCFP compared with the control or $\mathrm{T}$ were observed during the dosing period (Tables 3 and 5, respectively). Fibrobacter succinogenes is one of the most widespread cellulolytic bacteria in the rumen (Stewart et al., 1997), and it degrades plant cell walls by producing polysaccharidases, specifically, endoglucanases, xylanases, and cellulases (Stewart and Flint, 1989; Burnet et al., 2015). The greater abundances of Fibrobacteraceae and Fibrobacter with CL+SCFP agree with previous studies using yeast culture (Callaway and Martin, 1997; Zhu et al., 2017), but because no statistical differences between CL+SCFP and CL were found in our study, it is not clear whether Fibrobacter or Fibrobacteraceae stimulation was due to SCFP. More research is needed to ascertain the role of SCFP in the latter response. Others have reported associations between yeast culture or SCFP and fibrolytic bacteria. For instance, Callaway and Martin (1997) reported increased growth of the fibrolytic bacteria Fibrobacter succinogenes and Ruminococcus albus with the addition of a yeast culture extract to culture medium. In addition, Zhu et al.
(2017) reported greater populations of Ruminococcus albus, $R$. flavefaciens, and Fibrobacter succinogenes in the rumen when SCFP was fed to dairy cows.

The reduction in relative abundance of genus $\mathrm{Bu}$ tyrivibrio with the addition of CL+SCFP agrees with Pinloche et al. (2013), who reported that supplementing $0.5 \mathrm{~g} / \mathrm{d}$ live yeast to the diet of lactating cows decreased the relative abundance of Butyrivibrio from 3.26 to $1.65 \%$. Similarly, during the dosing period, the abundance of Butyrivibrio was lower in cows fed CL and CL+SCFP compared with T.

\section{Correlation Between Bacterial Abundance and Dairy Cow Performance}

Our correlation analysis only focused on the genuslevel identification. Due to the considerable physiological diversity within genera such as Prevotella, it is important to note that different OTU within the same genera may have positive or negative correlations with performance measures, depending on their functions. In addition, in the subsequent sections, the focus is on discussing the associations between performance measures and taxa regardless of their relative abundance. It should be noted that while certain minor abundance ( 0.5 to $1 \%$ abundance) bacteria alone have been associated with key nutrient metabolism or performance measures in dairy cows, such as Fibrobacter succinogenes or Ruminococcus flavefaciens with fiber digestion (Latham et al., 1978; Miron and Ben-Ghedalia, 1993; Stevenson and Weimer, 2007), minor abundance bacteria often act with others to influence rumen fermentation, nutrient metabolism, and performance measures. For instance, F. succinogenes and Prevotella ruminicola have synergistic effects on forage cellulose degradation, as reported by Osborne and Dehority (1989). Therefore, the ensuing results should be interpreted with caution because the relationship between specific genera and production responses needs further validation.

The negative correlation between relative abundance of Butyrivibrio and DMI, milk yield, and milk protein and lactose yields indicates that this bacterial group may be inefficient at using energy, although Butyrivibrio was reported to use a variety of substrates such as cellulose, protein, starch, and sugar (Russell, 2002). The implications of changes in the abundance of unclassified Clostridiales by feeding CL or CL+SCFP are unclear because little information is available on its function in the rumen. The negative correlation between the relative abundance of genus Prevotella and milk fat concentration are in agreement with findings from previous studies (Jami et al., 2014; Jiang et al., 2017a,b). Notably, OTU 816492 within genus Prevotella, which is most related to $P$. ruminicola 
based on sequence similarity in the National Center for Biotechnology Information (NCBI) database using the Basic Local Alignment Search Tool (https://blast.ncbi .nlm.nih.gov/Blast.cgi; Johnson et al., 2008), had the strongest negative relationship with milk fat content, and it should therefore be the subject of more research to understand its role.

The positive correlation between unclassified Succinivibrionaceae and DMI agrees with our previous study reporting positive correlation between Succinivibrionaceae and ADF digestibility as well DMI (Jiang et al., 2017a,b). However, the reason for the positive correlation is unknown because this unclassified Succinivibrionaceae group has not been cultured. Succinivibrionaceae is a bacterial family containing the genera Anaerobiospirillum, Ruminobacter, Succinimonas, and Succinivibrio. Some known species within the family are Ruminobacter (Bacteroides) amylophilus, Selenomonas ruminantium, and Succinivibrio dextrinosolvens, which digest starch, starch and sugar, and dextrins, respectively (Hobson and Stewart, 2012).

The positive correlation between Coprococcus and DMI, milk yield, and feed efficiency is in agreement with Jewell et al. (2015) and Shabat et al. (2016), who reported that cows with greater efficiency had higher ruminal abundance of Coprococcus. Some species within the genus Coprococcus have been cultured from human feces, such as C. catus, C. comes, and C. eutactus (Holdeman and Moore, 1974). In the rumen of dairy cows, C. catus was also reported to be more abundant in cows with lower methane emission and higher feed efficiency (Shabat et al., 2016). The efficient animals in that study had a higher abundance of genes aligned to the acrylate pathway, which is more efficient than the succinate pathway in converting lactate to propionate (Shabat et al., 2016). Future studies are needed to explore the contribution of this genus and C. catus to ruminal fermentation and dairy cow performance.

Limited information is available in the literature on ruminal function of YS2. However, the positive correlation between YS2 and yield of milk, FCM, and milk fat and lactose as well as feed efficiency suggests it plays an important role in the rumen. The positive correlation observed between S24-7 and milk fat and protein concentrations indicates that S24-7 might be related to fiber digestion or fermentable carbohydrate utilization. The negative correlations between the Succiniclasticum genus and DMI, milk yield, 3.5\% FCM yield, and production of milk fat, protein, and lactose suggest that certain species in this genus may negatively affect performance measures, but this possibility needs to be validated in research trials.

The ruminal abundance of the genus Methanobrevibacter is undesirable for improving dairy cow perfor- mance because of its negative correlation with DMI and milk yield. In agreement, Zhou et al. (2009) reported a 2-fold greater abundance of Methanobrevibacter sp. strain AbM4 in low-feed-efficient animals compared with high-feed-efficient animals. The bacterial species from Methanobrevibacter produce methane and greater abundance results in greater losses of energy as methane, explaining the negative correlation with dairy cow performance indicators (Beauchemin and McGinn, 2005; Zhou et al., 2009).

The negative correlation between unclassified Bacteroidales, unclassified Paraprevotellaceae, CF231, unclassified Ruminococcaceae, and several performance measures including DMI, milk yield, and 3.5\% FCM yield indicates ruminal abundance of these unclassified bacterial genera might contribute to reduced dairy cow performance. However, future studies are required to further explore their function and to study the effects of reducing their prevalence on performance of dairy cows.

\section{Candidate Bacteria for Future Studies}

The abundance of unclassified Succinivibrionaceae, unclassified YS2, Coprococcus, and Treponema was positively correlated with various performance parameters such as DMI, milk yield, and feed efficiency. This finding suggests that these taxa play important roles in improving dairy cow performance, and they should therefore be speciated, cultured, and examined as direct-fed microbials for dairy cow diets. In addition, additives such as SCFP could possibly be modified to enhance the relative abundance of these species.

\section{CONCLUSIONS}

In this study, we showed for the first time that the composition of ruminal bacteria was not affected by dietary $\mathrm{AFB}_{1}(63.4 \mu \mathrm{g} / \mathrm{kg})$ delivered as a pulse dose. Feeding CL with or without SCFP increased the abundance of the most dominant bacterial phylum Bacteroidetes when aflatoxin was not dosed in the rumen. However, when aflatoxin was fed, CL had no effect on the microbiome, but CL+SCFP increased the abundance of Fibrobacter, one of the major fibrolytic bacteria genera, compared with $\mathrm{T}$ and tended to increase the abundance compared with the control. Feeding aflatoxin at $63 \mu \mathrm{g} / \mathrm{kg}$, a common contamination level on farms, did not affect the abundance of dominant bacteria and rumen fermentation. Strong positive correlations existed between measurements of milk yield, DMI, and feed efficiency and the relative abundances of several dominant bacteria genera, such as unclassified Succinivibrionaceae, Coprococcus, and Treponema. 


\section{ACKNOWLEDGMENTS}

We gratefully acknowledge Diamond V Inc. (Cedar Rapids, IA) for funding the animal experiment. We thank the staff of the University of Florida (Gainesville) Dairy Unit for their assistance with the study. We also thank Anapaula Mayers (Daniel Alcides Carrion National University, Cerro De Pasco, Peru) for her help with the animal experiment.

\section{REFERENCES}

Arai, T., T. Ito, and Y. Koyama. 1967. Antimicrobial activity of aflatoxins. J. Bacteriol. 93:59-64.

Beauchemin, K. A., and S. M. McGinn. 2005. Methane emissions from feedlot cattle fed barley or corn diets. J. Anim. Sci. 83:653-661. https://doi.org/10.2527/2005.833653x.

Burnet, M. C., A. C. Dohnalkova, A. P. Neumann, M. S. Lipton, R. D. Smith, G. Suen, and S. J. Callister. 2015. Evaluating models of cellulose degradation by Fibrobacter succinogenes S85. PLoS One 10:e0143809. https://doi.org/10.1371/journal.pone.0143809.

Callaway, E. S., and S. A. Martin. 1997. Effects of a Saccharomyces cerevisiae culture on ruminal bacteria that utilize lactate and digest cellulose. J. Dairy Sci. 80:2035-2044. https://doi.org/10 .3168/jds.S0022-0302(97)76148-4.

Caporaso, J. G., J. Kuczynski, J. Stombaugh, K. Bittinger, F. D. Bushman, E. K. Costello, N. Fierer, A. Gonzalez Pena, J. K. Goodrich, J. I. Gordon, G. A. Huttley, S. T. Kelley, D. Knights, J. E. Koenig, R. E. Ley, C. A. Lozupone, D. McDonald, B. D. Muegge, M. Pirrung, J. Reeder, J. R. Sevinsky, P. J. Turnbaugh, W. A. Walters, J. Widmann, T. Yatsunenko, J. Zaneveld, and R. Knight. 2010. QIIME allows analysis of high-throughput community sequencing data. Nat. Methods 7:335-336. https://doi.org/10.1038/ nmeth.f.303.

Cavalcanti, C. A., N. A. Andreollo, and W. A. Santos. 2005. Cervical esophagostomy using indwelling catheter for analysis of gastric physiology in dogs. Acta Cir. Bras. 20:405-407. https://doi.org/10 $.1590 /$ S0102-86502005000500012.

DeSantis, T. Z., P. Hugenholtz, N. Larsen, M. Rojas, E. L. Brodie, K. Keller, T. Huber, D. Dalevi, P. Hu, and G. L. Andersen. 2006. Greengenes, a chimera-checked 16S rRNA gene database and workbench compatible with ARB. Appl. Environ. Microbiol. 72:5069-5072. https://doi.org/10.1128/AEM.03006-05.

Diaz, D. E., W. M. Hagler, J. T. Blackwelder, J. A. Eve, B. A. Hopkins, K. L. Anderson, F. T. Jones, and L. W. Whitlow. 2004. Aflatoxin binders II: Reduction of aflatoxin M1 in milk by sequestering agents of cows consuming aflatoxin in feed. Mycopathologia 157:233-241. https://doi.org/10.1023/b:myco.0000020587.93872 .59 .

Edgar, R. C. 2010. Search and clustering orders of magnitude faster than BLAST. Bioinformatics 26:2460-2461. https://doi.org/10 .1093/bioinformatics/btq461.

FASS. 2010. Guide for the Care and Use of Agricultural Animals in Research and Teaching. 3rd ed. Federation of Animal Science Societies, Champaign, IL

Gallo, A., M. Moschini, and F. Masoero. 2008. Aflatoxins absorption in the gastro-intestinal tract and in the vaginal mucosa in lactating dairy cows. Ital. J. Anim. Sci. 7:53-63. https://doi.org/10.4081/ ijas.2008.53.

Hill, T. C. J., K. A. Walsh, J. A. Harris, and B. F. Moffett. 2003. Using ecological diversity measures with bacterial communities. FEMS Microbiol. Ecol. 43:1-11. https://doi.org/10.1111/j.1574 -6941.2003.tb01040.x.

Hobson, P. N., and C. S. Stewart, ed. 2012. The Rumen Microbial Ecosystem. Springer Science \& Business Media, Berlin, Germany.

Holdeman, L. V., and W. E. C. Moore. 1974. New genus, Coprococcus, twelve new species, and emended descriptions of four previously described species of bacteria from human feces. Int. J. Syst. Evol. Microbiol. 24:260-277.

Jami, E., and I. Mizrahi. 2012. Composition and similarity of bovine rumen microbiota across individual animals. PLoS One 7:e33306. https://doi.org/10.1371/journal.pone.0033306.

Jami, E., B. A. White, and I. Mizrahi. 2014. Potential role of the bovine rumen microbiome in modulating milk composition and feed efficiency. PLoS One 9:e85423. https://doi.org/10.1371/journal .pone.0085423.

Jewell, K. A., C. A. McCormick, C. L. Odt, P. J. Weimer, and G. Suen. 2015. Ruminal bacterial community composition in dairy cows is dynamic over the course of two lactations and correlates with feed efficiency. Appl. Environ. Microbiol. 81:4697-4710. https://doi.org/10.1128/AEM.00720-15.

Jiang, Y., I. M. Ogunade, D. H. Kim, X. Li, A. A. Pech-Cervantes, K. G. Arriola, A. S. Oliveira, J. P. Driver, L. F. Ferraretto, C. R. Staples, D. Vyas, and A. T. Adesogan. 2018. Effect of adding clay with or without a Saccharomyces cerevisiae fermentation product on the health and performance of lactating dairy cows challenged with dietary aflatoxin B1. J. Dairy Sci. 101:3008-3020. https://doi .org/10.3168/jds.2017-13678.

Jiang, Y., I. M. Ogunade, S. Qi, K. G. Arriola, S. Qi, D. Vyas, C. R. Staples, and A. T. Adesogan. 2017a. Effects of the dose and viability of Saccharomyces cerevisiae. 2. Ruminal fermentation, performance of lactating dairy cows and correlations between ruminal bacteria abundance and performance measures. J. Dairy Sci. 100:8102-8118. https://doi.org/10.3168/jds.2016-12371.

Jiang, Y., I. M. Ogunade, S. Qi, T. J. Hackmann, C. R. Staples, and A. T. Adesogan. 2017b. Effects of the dose and viability of Saccharomyces cerevisiae. 1. Diversity of ruminal microbes as analyzed by Illumina MiSeq sequencing and quantitative PCR. J. Dairy Sci. 100:325-342. https://doi.org/10.3168/jds.2016-11263.

Jiang, Y. H., H. J. Yang, and P. Lund. 2012. Effect of aflatoxin B1 on in vitro ruminal fermentation of rations high in alfalfa hay or ryegrass hay. Anim. Feed Sci. Technol. 175:85-89. https://doi.org/ 10.1016/j.anifeedsci.2012.03.021.

Johnson, M., I. Zaretskaya, Y. Raytselis, Y. Merezhuk, S. McGinnis, and T. L. Madden. 2008. NCBI BLAST: A better web interface. Nucleic Acids Res. 36:W5-W9.

Kiessling, K. H., H. Pettersson, K. Sandholm, and M. Olsen. 1984. Metabolism of aflatoxin, ochratoxin, zearalenone, and three trichothecenes by intact rumen fluid, rumen protozoa, and rumen bacteria. Appl. Environ. Microbiol. 47:1070-1073.

Kozich, J. J., S. L. Westcott, N. T. Baxter, S. K. Highlander, and P. D. Schloss. 2013. Development of a dual-index sequencing strategy and curation pipeline for analyzing amplicon sequence data on the MiSeq Illumina sequencing platform. Appl. Environ. Microbiol. 79:5112-5120. https://doi.org/10.1128/AEM.01043-13.

Kutz, R. E., J. D. Sampson, L. B. Pompeu, D. R. Ledoux, J. N. Spain, M. Vazquez-Anon, and G. E. Rottinghaus. 2009. Efficacy of Solis, NovasilPlus, and MTB-100 to reduce aflatoxin M1 levels in milk of early to mid lactation dairy cows fed aflatoxin B1. J. Dairy Sci. 92:3959-3963. https://doi.org/10.3168/jds.2009-2031.

Latham, M. J., B. E. Brooker, G. L. Pettipher, and P. J. Harris 1978. Ruminococcus flavefaciens cell coat and adhesion to cotton cellulose and to cell walls in leaves of perennial ryegrass (Lolium perenne). Appl. Environ. Microbiol. 35:156-165.

Lodge-Ivey, S. L., J. Browne-Silva, and M. B. Horvath. 2009. Bacterial diversity and fermentation end products in rumen fluid samples collected via oral lavage or rumen cannula. J. Anim. Sci. 87:23332337. https://doi.org/10.2527/jas.2008-1472.

Lozupone, C., and R. Knight. 2005. UniFrac: A new phylogenetic method for comparing microbial communities. Appl. Environ. Microbiol. 71:8228-8235. https://doi.org/10.1128/AEM.71.12.8228 -8235.2005 .

Lozupone, C., M. E. Lladser, D. Knights, J. Stombaugh, and R. Knight. 2011. UniFrac: An effective distance metric for microbial community comparison. ISME J. 5:169-172. https://doi.org/10 .1038 /ismej.2010.133.

Miron, J., and D. Ben-Ghedalia. 1993. Digestion of cell-wall monosaccharides of ryegrass and alfalfa hays by the ruminal bacteria 
Fibrobacter succinogenes and Butyrivibrio fibrisolvens. Can. J. Microbiol. 39:780-786.

Muck, R. E., and J. T. Dickerson. 1988. Storage temperature effects on proteolysis in alfalfa silage. Trans. ASABE 31:1005-1009. https:// doi.org/10.13031/2013.30813.

Noel, R. J., and L. G. Hambleton. 1976. Collaborative study of a semiautomated method for determination of crude protein in animal feeds. J. Assoc. Off. Anal. Chem. 59:134-140.

Ogunade, I. M., C. Martinez-Tuppia, O. C. M. Queiroz, Y. Jiang, P. Drouin, F. Wu, D. Vyas, and A. T. Adesogan. 2018. Silage review: Mycotoxins in silage: Occurrence, effects, prevention, and mitigation. J. Dairy Sci. 101:4034-4059. https://doi.org/10.3168/ jds.2017-13788.

Osborne, J. M., and B. A. Dehority. 1989. Synergism in degradation and utilization of intact forage cellulose, hemicellulose, and pectin by three pure cultures of ruminal bacteria. Appl. Environ. Microbiol. 55:2247-2250. https://doi.org/10.1111/j.1365-2672.1994 .tb04399.x.

Pinloche, E., N. McEwan, J.-P. Marden, C. Bayourthe, E. Auclair, and C. J. Newbold. 2013. The effects of a probiotic yeast on the bacterial diversity and population structure in the rumen of cattle. PLoS One 8:e67824. https://doi.org/10.1371/journal.pone.0067824.

Queiroz, O. C. M., J. H. Han, C. R. Staples, and A. T. Adesogan. 2012. Effect of adding a mycotoxin-sequestering agent on milk aflatoxin M1 concentration and the performance and immune response of dairy cattle fed an aflatoxin B1-contaminated diet. J. Dairy Sci. 95:5901-5908. https://doi.org/10.3168/jds.2011-5287.

Rodrigues, I., and K. Naehrer. 2012. A three-year survey on the worldwide occurrence of mycotoxins in feedstuffs and feed. Toxins (Basel) 4:663-675. https://doi.org/10.3390/toxins4090663.

Russell, J. 2002. Rumen Microbiology and its Role in Ruminant Nutrition. Cornell University, Ithaca, NY.

Shabat, S. K., G. Sasson, A. Doron-Faigenboim, T. Durman, S. Yaacoby, M. E. Berg Miller, B. A. White, N. Shterzer, and I. Mizrahi. 2016. Specific microbiome-dependent mechanisms underlie the energy harvest efficiency of ruminants. ISME J. 10:2958-2972.

Sinha, R. R. P., and S. P. Arora. 1982. Influence of different levels of aflatoxins on rumen fermentation (in vitro). J. Nucl. Agric. Biol. 11:87-89.

Stevenson, D. M., and P. J. Weimer. 2007. Dominance of Prevotella and low abundance of classical ruminal bacterial species in the bovine rumen revealed by relative quantification real-time PCR. Appl. Microbiol. Biotechnol. 75:165-174. https://doi.org/10.1007/ s00253-006-0802-y.

Stewart, C. S., and H. J. Flint. 1989. Bacteroides (Fibrobacter) succinogenes, a cellulolytic anaerobic bacterium from the gastrointestinal tract. Appl. Microbiol. Biotechnol. 30:433-439. https://doi .org/10.1007/bf00263846.

Stewart, C. S., H. J. Flint, and M. P. Bryant. 1997. The rumen bacteria. Pages 10-72 in The Rumen Microbial Ecosystem. P. N. Hobson and C. S. Stewart, ed. Blackie, London, UK.

Strobel, E., K. Seeling, and C. C. Tebbe. 2008. Diversity responses of rumen microbial communities to Fusarium-contaminated feed, evaluated with rumen simulating technology. Environ. Microbiol. 10:483-496. https://doi.org/10.1111/j.1462-2920.2007.01469.x.
Sulzberger, S. A., S. Melnichenko, and F. C. Cardoso. 2017. Effects of clay after an aflatoxin challenge on aflatoxin clearance, milk production, and metabolism of Holstein cows. J. Dairy Sci. 100:18561869. https://doi.org/10.3168/jds.2016-11612.

Upadhaya, S. D., M. A. Park, and J. K. Ha. 2010. Mycotoxins and their biotransformation in the rumen: A review. Asian-Australasian J. Anim. Sci. 23:1250-1260. https://doi.org/10.5713/ajas.2010.r.06.

Wang, J., L. Tang, T. C. Glenn, and J. S. Wang. 2016. Aflatoxin B1 induced compositional changes in gut microbial communities of male F344 rats. Toxicol. Sci. 150:54-63. https://doi.org/10.1093/ toxsci/kfv259.

Westlake, K., R. I. Mackie, and M. F. Dutton. 1987. Effects of several mycotoxins on specific growth rate of Butyrivibrio fibrisolvens and toxin degradation in vitro. Appl. Environ. Microbiol. 53:613-614.

Westlake, K., R. I. Mackie, and M. F. Dutton. 1989. In vitro metabolism of mycotoxins by bacterial, protozoal and ovine ruminal fluid preparations. Anim. Feed Sci. Technol. 25:169-178. https://doi .org/10.1016/0377-8401(89)90117-x.

Wu, F. 2006. Mycotoxin reduction in Bt corn: Potential economic, health, and regulatory impacts. Transgenic Res. 15:277-289. https: //doi.org/10.1007/s11248-005-5237-1.

Wu, S., R. L. Baldwin, W. Li, C. Li, E. E. Connor, and R. W. Li. 2012. The bacterial community composition of the bovine rumen detected using pyrosequencing of 16s rRNA genes. Metagenomics (Cairo) 1:1-11. https://doi.org/10.4303/mg/235571.

Xiong, J. L., Y. M. Wang, T. D. Nennich, Y. Li, and J. X. Liu. 2015. Transfer of dietary aflatoxin B1 to milk aflatoxin M1 and effect of inclusion of adsorbent in the diet of dairy cows. J. Dairy Sci. 98:2545-2554. https://doi.org/10.3168/jds.2013-7842.

Zain, M. E. 2011. Impact of mycotoxins on humans and animals. J. Saudi Chem. Soc. 15:129-144. https://doi.org/10.1016/s0300 $-483 \mathrm{x}(01) 00471-1$.

Zhou, M., E. Hernandez-Sanabria, and L. L. Guan. 2009. Assessment of the microbial ecology of ruminal methanogens in cattle with different feed efficiencies. Appl. Environ. Microbiol. 75:6524-6533. https://doi.org/10.1128/AEM.02815-08.

Zhu, W., Z. Wei, N. Xu, F. Yang, I. Yoon, Y. Chung, J. Liu, and J. Wang. 2017. Effects of Saccharomyces cerevisiae fermentation products on performance and rumen fermentation and microbiota in dairy cows fed a diet containing low quality forage. J. Anim. Sci. Biotechnol. 8:36. https://doi.org/10.1186/s40104-017-0167-3.

\section{ORCIDS}

Y. Jiang (®) https://orcid.org/0000-0002-4590-2361

I. M. Ogunade ๑ https://orcid.org/0000-0003-3875-6156

A. A. Pech-Cervantes (1) https://orcid.org/0000-0003-4709-9098

K. G. Arriola @ https://orcid.org/0000-0001-6032-8188

D. Vyas () https://orcid.org/0000-0002-7657-0267

A. T. Adesogan ( ) https://orcid.org/0000-0003-1020-7526 